\title{
Redox-Rich Metallocene Tetrazene Complexes: Synthesis, Structure, Electrochemistry, and Catalysis
}

\author{
Stefan Vanicek, ${ }^{\dagger}$ Markus Jochriem, ${ }^{\dagger}$ Christopher Hassenrück, ${ }^{\dagger}$ Souvik Roy, ${ }^{\S}$ Holger Kopacka, ${ }^{\dagger}$
}

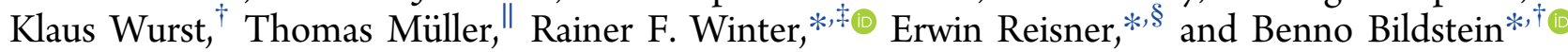

${ }^{\dagger}$ Institute of General, Inorganic and Theoretical Chemistry, Center for Chemistry and Biomedicine, University of Innsbruck, Innrain 80-82, A-6020 Innsbruck, Austria

${ }^{\ddagger}$ Department of Chemistry, University of Konstanz, Universitätsstrasse 10, D-78457 Konstanz, Germany

${ }^{\S}$ Christian Doppler Laboratory for Sustainable SynGas Chemistry, Department of Chemistry, University of Cambridge, Lensfield Road, Cambridge CB2 1EW, U.K.

"Institute of Organic Chemistry, Center for Chemistry and Biomedicine, University of Innsbruck, Innrain 80-82, A-6020 Innsbruck, Austria

Supporting Information

ABSTRACT: Thermal or photochemical metal-centered cycloaddition reactions of azidocobaltocenium hexafluoridophosphate or azidoferrocene with (cyclooctadiene)(cyclopentadienyl)cobalt(I) afforded the first metallocenyl-substituted tetrazene cyclopentadienyl cobalt complexes together with azocobaltocenium or azoferrocene as side products. The trimetallic CpCo compounds are highly conjugated, colored, and redox-active metallo-aromatic compounds, as shown by their spectroscopic, structural, and electrochemical properties. The CpCo-tetrazenido complex with two terminally appended cobaltocene units catalyzes electrochemical proton reduction from acetic acid at a mild overpotential $(0.35 \mathrm{~V})$. Replacing cobaltocene with ferrocene moieties rendered the

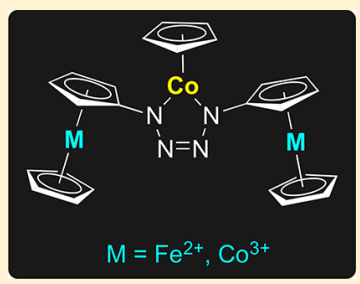
complex inactive toward catalysis.

\section{INTRODUCTION}

Tetraaza-1,3-butadiene ("tetrazene") ligands ( $\mathrm{R}-\mathrm{N}=\mathrm{N}-\mathrm{N}=$ $\mathrm{N}-\mathrm{R}$ ) are unstable as free ligands but can be prepared in situ from organic alkyl or aryl azides in the coordination sphere of suitable middle- to late-transition-metal fragments, ${ }^{1}$ thereby affording stable metallo-aromatic compounds. ${ }^{2}$ The main interest in metal-tetrazene complexes stems from their intriguing electronic structures ${ }^{1,2}$ due to the often redoxnoninnocent character of the tetrazene ligand (Scheme 1). The latter may exist as a diamagnetic neutral (A), paramagnetic monoanionic (B), or diamagnetic dianionic (C) species, depending on the redox potential of the coordinated metal/ coligand entity. ${ }^{2}$

In this contribution, we combine tetrazene coordination chemistry with metallocene chemistry, aiming at electronically and catalytically interesting, redox-responsive compounds. Using recently accessible azidocobaltocenium hexafluoridophosphate $\left(\mathrm{CcN}_{3}{ }^{+} \mathrm{PF}_{6}{ }^{-} ; \mathrm{Cc}=\text { cobaltoceniumyl }\right)^{3}$ and azidoferrocene $\left(\mathrm{FcN}_{3}, \mathrm{Fc}=\text { ferrocenyl }\right)^{4}$ as starting materials, we report on the first metallocenyl-substituted tetrazene cyclopentadienyl-cobalt ( $\mathrm{CpCo}$ ) complexes. The choice of cobaltoceniumyl and ferrocenyl substituents as well as $\mathrm{CpCo}$ as the central metal fragment is governed by their very well behaved reversible redox chemistry. In combination with the highly conjugated, quasi-aromatic $\mathrm{CpCo}$ (tetrazene) "cobaltole" metallacycles, we expect rich electrochemistry, switchable redox states, and potential applications in photo or redox catalysis: e.g., in artificial photosynthesis for solar-driven water
Scheme 1. Electronic Structures of Redox-Noninnocent Tetrazene Ligands and Tetrazenido Complexes ${ }^{a}$
A<smiles>[R]N=NN=N[R]</smiles>

B<smiles>[R]N=NN=N[R]</smiles>

C

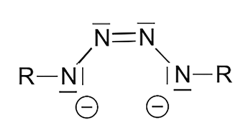<smiles>[R]N1N=NN([Y9])N1C</smiles><smiles></smiles><smiles>[Y][Y16]1N([R])N=NN1[R]</smiles>

${ }^{a}$ Abbreviations: $\mathrm{R}=$ alkyl or aryl; $\mathrm{M}=$ middle to late transition metal; $\mathrm{L}=$ coligand.

Special Issue: Organometallic Electrochemistry: Redox Catalysis Going the Smart Way

Received: September 17, 2018

Published: November 8, 2018 
splitting. ${ }^{5}$ Furthermore, the highly polar, cationic cobaltoceniumyl substituents allow solubility in polar solvents such as water, an advantageous feature for green chemistry applications. Ferrocenyl and cobaltoceniumyl moieties have inversely addressable redox couples (Fc, $\mathrm{Fe}(\mathrm{II}) / \mathrm{Fe}(\mathrm{III}) ; \mathrm{Cc}, \mathrm{Co}(\mathrm{III}) /$ $\mathrm{Co}(\mathrm{II}) / \mathrm{Co}(\mathrm{I})$ ), which will allow a study of the influence of this difference in redox-catalytic applications.

\section{RESULTS AND DISCUSSION}

Synthesis. CpCo tetrazene complexes have been known for 50 years and are prepared by thermal reaction of an excess of an alkyl or more commonly an aryl azide with cobaltocene or dicarbonyl(cyclopentadienyl)cobalt(I), respectively. ${ }^{1,2 a, d, e}$ These reactions are far from being chemoselective and usually afford rather low yields $(<50 \%)$ with unidentified diamagnetic and paramagnetic byproducts. In contrast to these simple organic azide substrates, ${ }^{2 \mathrm{a}, \mathrm{d}, \mathrm{e}}$ the organometallic starting materials $\mathrm{CcN}_{3}{ }^{+} \mathrm{PF}_{6}^{-}$(1) and $\mathrm{FcN}_{3}$ (2) required distinct reaction conditions, due to their different polarities, charges, and donor/acceptor character (Scheme 2).

Scheme 2. Synthesis of Tetrazene Complexes 4 and 5 and Azometallocenes 6 and 7

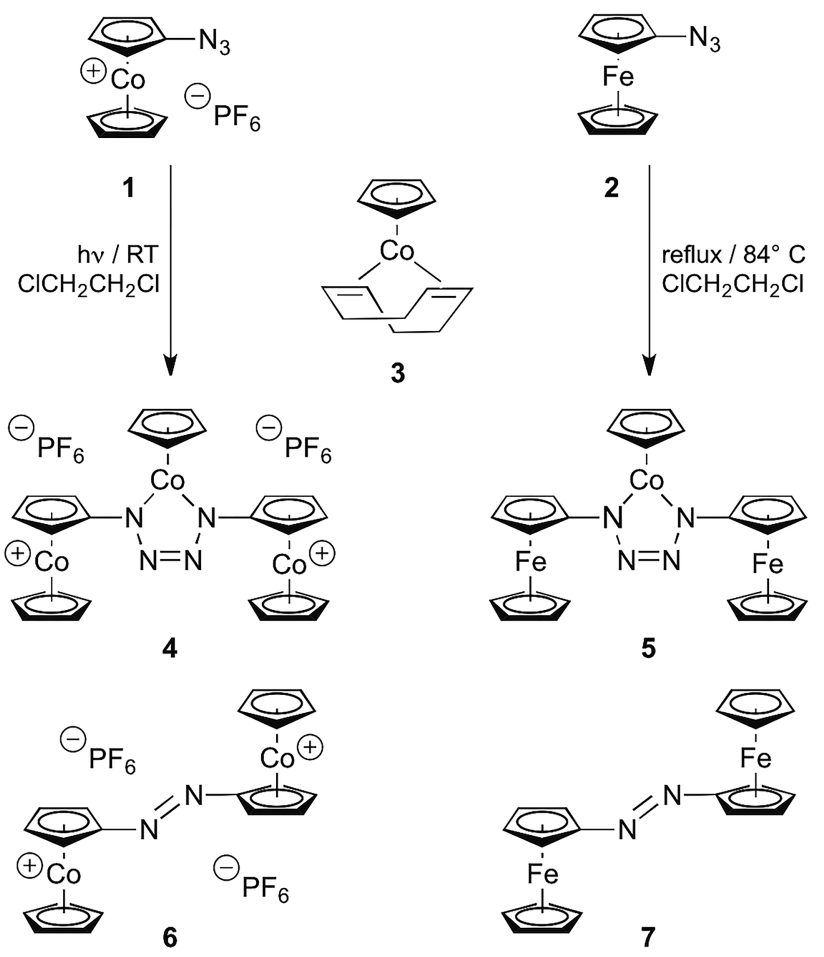

We found that, as a starting material for the CpCo fragment of the tetrazene complexes, cyclooctadiene(cyclopentadienyl)cobalt $(\mathrm{I})^{6}(3)$ is superior to the traditionally used dicarbonyl(cyclopentadienyl)cobalt(I), ${ }^{1,2 a, d, e}$ which is easily rationalized by the more labile diolefin ligand in comparison to strong-field CO ligands. The generally assumed mechanism of these reactions involves initial formation of a metal-nitrene/imido complex with elimination of $\mathrm{N}_{2}$ followed by a $[2+3]$ cycloaddition reaction with a second equivalent of the azide. ${ }^{1}$ Due to these singlet/triplet-nitrene $((\mathrm{S} / \mathrm{T})$-nitrene) intermediates, their dimerization via their $\mathrm{T}$-nitrenes to 1,2diazenes (azo compounds) is always encountered in these reactions, depending on the reaction conditions and on the

population of the $\mathrm{T}$ state. To maximize the yield of the desired tetrazene complexes $\mathbf{4}$ and $\mathbf{5}$, the formation of their T-nitrenes has therefore to be suppressed as much as possible. It is wellknown that acceptor-substituted nitrenes, e.g. pentafluorophenylnitrene, ${ }^{7}$ predominantly exist in the $S$ state. Cationic cobaltoceniumyl is a strongly electron withdrawing group. Therefore, it proved possible to synthesize dicobaltoceniumyltetrazene complex $\mathbf{4}$ by photochemical activation of azidocobaltocenium hexafluoridophosphate ${ }^{3}$ (1) at room temperature in an excellent yield of $90 \%$ in the crude product mixture according to NMR analysis. Byproducts include only $1 \%$ of azocobaltocenium bis(hexafluoridophosphate) (6) and $6 \%$ of aminocobaltocenium hexafluoridophosphate $(8){ }^{3}$ formed via hydrogen abstraction by cobaltoceniumylnitrene from the solvent. However, as is always the case in cobaltocenium chemistry, purification of mixtures of (di)cationic species is challenging, as chromatographic separation is usually not possible. Purification by fractional crystallization resulted in a severe loss of material, providing analytically pure 6 in 57\% yield (see the Experimental Section). It is remarkable that such a photochemical route is possible at all, given the fact that known aryl tetrazene-CpCo complexes (aryl = phenyl, pentafluorophenyl $)^{2 \mathrm{e}}$ are photochemically unstable. Dicationic tetrazene complex 4 therefore represents a photochemically as well as thermally stable compound (no degradation during $6 \mathrm{~h}$ of irradiation with a $700 \mathrm{~W}$ high-pressure mercury lamp; mp > $300{ }^{\circ} \mathrm{C}$ ), properties that are highly beneficial for potential applications in photo/redox catalysis in polar media (vide infra).

In contrast to azidocobaltocenium hexafluoridophosphate (1), azidoferrocene ${ }^{4}(\mathbf{2})$ is a donor-substituted, slightly air and light sensitive azide. In this work, an improved and reliable synthetic protocol for $\mathbf{2}$ was developed (see the Experimental Section), making it now available in $89 \%$ yield, a significant improvement over the reported yield of $69 \%{ }^{4 \mathrm{~b}}$ Since diferrocenyl-tetrazene complex $\mathbf{5}$ proved to be unstable toward air and light (vide infra), no photochemical synthesis was possible. Reaction of $\mathbf{2}$ with $\mathbf{3}$ at room temperature gave no satisfactory conversion; therefore, thermal activation proved necessary (Scheme 2). Unfortunately, under these conditions the desired $\mathbf{5}$ is obtained after chromatographic workup in only $22 \%$ yield, together with $15 \%$ of azoferrocene ${ }^{8} 7$, the dimerization product of $\mathrm{T}$-ferrocenylnitrene. Whereas azoferrocene 7 is a known compound that has been frequently studied, ${ }^{8}$ its cobaltocenium analogue 6 represents a new dimetallocenyldiazene of interest in electrochemistry. To make 6 available on a preparative scale, a chemoselective synthesis via oxidation of aminocobaltocenium hexafluoridophosphate (8) was developed (Scheme 3). After some screening of potential oxidizing agents, the $\mathrm{HgO} / \mathrm{I}_{2}$ reagent ${ }^{9}$ proved best suited for our purposes, affording 6 in $87 \%$ isolated yield. In contrast to photolabile azoferrocene 7 , azocobaltocenium bis(hexafluoridophosphate) (6) is a highly stable, polar

Scheme 3. Synthesis of Azocobaltocenium 6

2

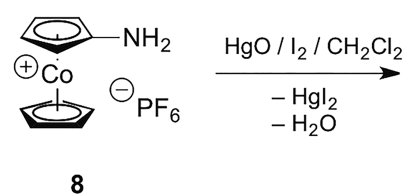

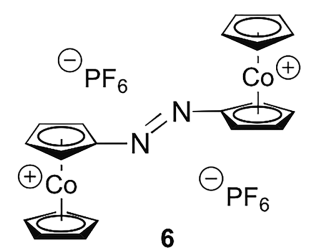


compound, soluble even in water (see the Experimental Section).

Solid-State Structures. Single-crystal structure analyses are available for all three of the new products 4-6 (Figures $1-3)$. Overall, these cobaltoceniumyl-substituted compounds

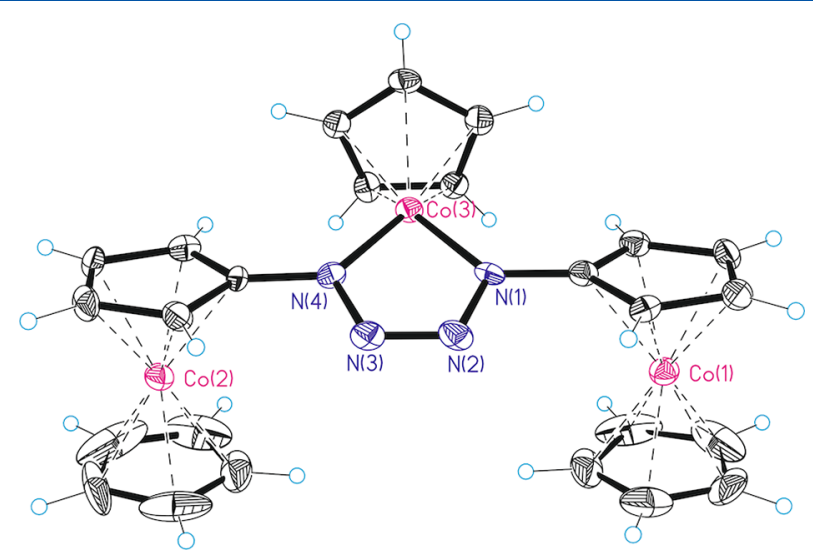

Figure 1. Molecular structure of the dication of 4 with thermal ellipsoids at the $30 \%$ probability level. Selected bond lengths $(\AA)$ : $\mathrm{N}(1)-\mathrm{N}(2)=1.365(9), \mathrm{N}(2)-\mathrm{N}(3)=1.272(9), \mathrm{N}(3)-\mathrm{N}(4)=$ $1.367(8), \mathrm{N}(1)-\mathrm{Co}(3)=1.834(7), \mathrm{N}(4)-\mathrm{Co}(3)=1.832(6)$.

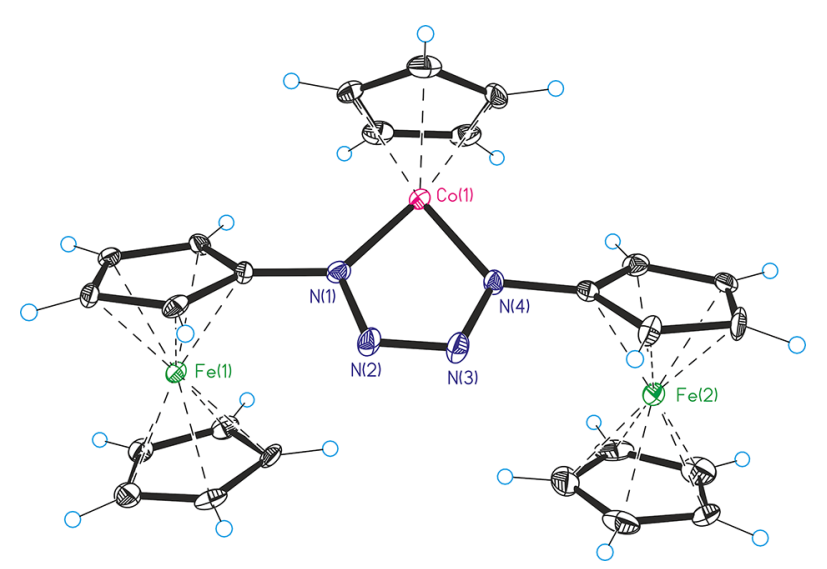

Figure 2. Molecular structure of 5 with thermal ellipsoids at the $30 \%$ probability level. Selected bond lengths $(\AA): \mathrm{N}(1)-\mathrm{N}(2)=1.351(5)$, $\mathrm{N}(2)-\mathrm{N}(3)=1.293(5), \mathrm{N}(3)-\mathrm{N}(4)=1.348(5), \mathrm{N}(1)-\mathrm{Co}(3)=$ $1.819(4), \mathrm{N}(4)-\mathrm{Co}(3)=1.826(4)$.

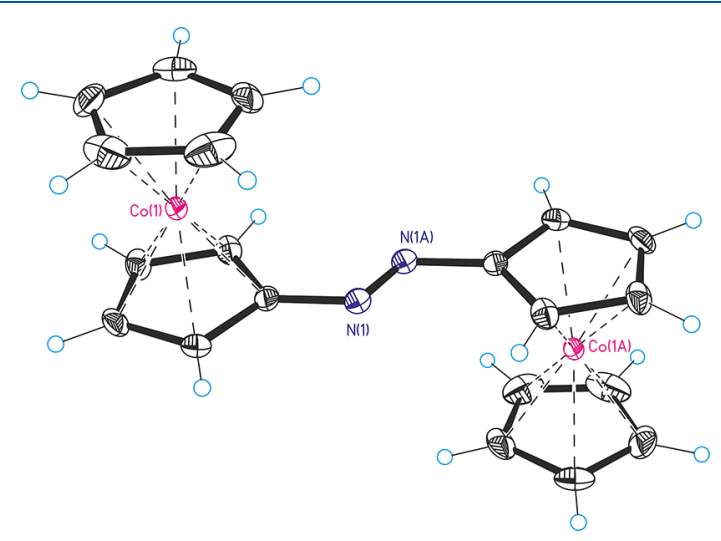

Figure 3. Molecular structure of the dication of 6 with thermal ellipsoids at the $30 \%$ probability level. Selected bond lengths $(\AA)$ : $\mathrm{N}(1)-\mathrm{N}(1 \mathrm{~A})=1.254(3)$. contain regular, undistorted cobaltocenium moieties with structural metrics comparable to those of other monofunctionalized cobaltocenium derivatives. ${ }^{3,10}$ The two tetrazene complexes $\mathbf{4}$ and $\mathbf{5}$ have similar tetraazacobalta metallacycles, comparable to that of bis(pentafluorophenyl)tetrazene(cyclopentadienyl)cobalt. ${ }^{2 \mathrm{~d}}$ Most importantly, the central N$\mathrm{N}$ bonds $(4, \mathrm{~N}(2)-\mathrm{N}(3)=1.272(9) \AA ; 5 \mathrm{~N}(2)-\mathrm{N}(3)=$ $1.292(5) \AA)$ are shorter than the terminal $\mathrm{N}-\mathrm{N}$ bonds (4, $\mathrm{N}(1)-\mathrm{N}(2)=1.365(9) \AA, \mathrm{N}(3)-\mathrm{N}(4)=1.367(8) \AA$; 5, $\mathrm{N}(1)-\mathrm{N}(2)=1.351(5) \AA, \mathrm{N}(3)-\mathrm{N}(4)=1.348(5) \AA)$, supporting the proposition that the electronic structure $\mathbf{C}$ of Scheme 1 is the accurate description in both cases. These dianionic ligands are therefore named in the following as "tetrazenido" ligands and the oxidation state $3+$ is assigned to the central cobalt of these compounds. Although dicationic dicobaltoceniumyl-tetrazenido complex 4 and neutral diferrocenyl-tetrazenido complex $\mathbf{5}$ differ in their overall charge, their peripheral metallocen(ium)yl substituents are arranged in a similar syn conformation, most likely due to steric constraints imposed by the central CpCo moieties.

The molecular structure of azocobaltocenium 6 (Figure 3) shows the expected trans conformation of the azo moiety with cobaltoceniumyl substituents arranged in the electrostatically preferred anti conformation. Bond lengths and angles are in line with expectations. Overall, the structure of $\mathbf{6}$ is very similar to the published structure of its neutral azoferrocene $\mathrm{e}^{2 \mathrm{~d}}$ analogue.

Spectroscopic Properties. ${ }^{1} \mathrm{H}$ NMR spectra of tetrazenido complexes $\mathbf{4}$ and $\mathbf{5}$ and of azocobaltocenium $\mathbf{6}$ showed the common pattern of monosubstituted metallocene groups ( $\mathrm{s}$, $5 \mathrm{H}$; pseudo-t, $2 \mathrm{H}$; pseudo-t, $2 \mathrm{H}$ ) with signals shifted to lower field for cobaltoceniumyl substituents $(>5.5 \mathrm{ppm})$ in comparison to those of ferrocenyl substituents $(<5.5 \mathrm{ppm})$ (see the Experimental Section and spectra in the Supporting Information). The additional $\mathrm{Cp}$ ligand in tetrazenido complexes 4 and 5 gave rise to an additional singlet of $50 \%$ intensity in comparison to the corresponding signals of the unsubstituted $\mathrm{Cp}$ rings of the two peripheral metallocene(ium)yl groups. ${ }^{13} \mathrm{C}$ NMR spectra displayed the expected number of signals for symmetrically substituted compounds, and cobaltoceniumyl signals were again observed generally at lower field $(>75 \mathrm{ppm})$ in comparison to ferrocenyl signals $(<75 \mathrm{ppm})$, except for signals of the quaternary carbons (4, $129.0 \mathrm{ppm}$; 5, $115.4 \mathrm{ppm}$; 6, $119.3 \mathrm{ppm}$ ), indicating CpCotetrazenido to be a weaker donor in comparison to the azo group. The signals of the $\mathrm{CpCo}$ moiety were observed close to those of the metallocene(ium)yl groups (4, $81.1 \mathrm{ppm} ; 5$, 78.2 $\mathrm{ppm})$, indicating the pseudoaromatic character of the tetrazenido ligand framework.

Further spectroscopic characterization included HRMS, IR, and $\mathrm{UV} /$ vis data. High-resolution mass spectrometry of 4-6 gave signals of molecular ions in excellent agreement with calculated values, thereby proving further the identity of these compounds. In the IR spectra of dicationic tetrazenido complex 4 and azocobaltocenium 6 the presence of the hexafluoridophosphate counterions was clearly evident from the strong diagnostic $\nu_{\mathrm{P}-\mathrm{F}}$ absorptions ${ }^{11}$ observed at approximately 815 and $550 \mathrm{~cm}^{-1}$ (see the Experimental Section and spectra in the Supporting Information).

Compounds 4 (red), 5 (green), and 6 (orange) are highly colored organometallic chromophores. Figure 4 gives a comparison of the two tetrazenido complexes $\mathbf{4}$ and $\mathbf{5}$, whereas Figure 5 compares azocobaltocenium 6 with its known 


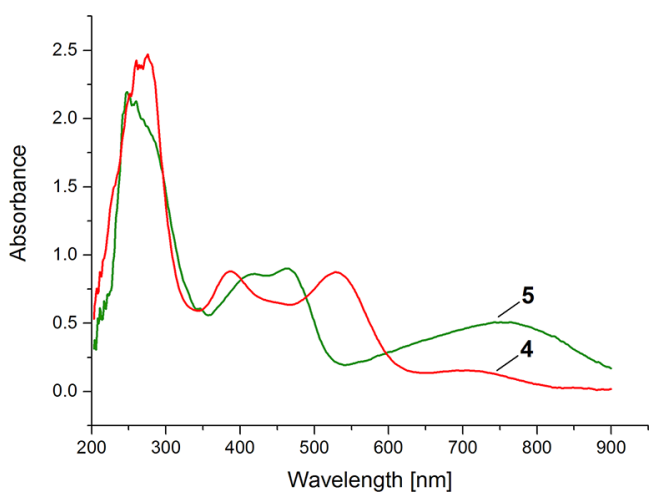

Figure 4. UV-vis spectra of tetrazenido complexes. $4\left(\mathrm{CH}_{3} \mathrm{CN}\right): \lambda_{\max }$ $388 \mathrm{~nm}\left(\varepsilon=8865 \mathrm{~L} \mathrm{~mol}^{-1} \mathrm{~cm}^{-1}\right), \lambda_{\max } 528 \mathrm{~nm}\left(\varepsilon=8805 \mathrm{~L} \mathrm{~mol}^{-1}\right.$ $\left.\mathrm{cm}^{-1}\right), \lambda_{\max }=706 \mathrm{~nm}\left(\varepsilon=1551 \mathrm{~L} \mathrm{~mol}^{-1} \mathrm{~cm}^{-1}\right) .5\left(\mathrm{CH}_{2} \mathrm{Cl}_{2}\right): \lambda_{\max } 419$ $\mathrm{nm}\left(\varepsilon=6807 \mathrm{~L} \mathrm{~mol}^{-1} \mathrm{~cm}^{-1}\right), \lambda_{\max } 462 \mathrm{~nm}\left(\varepsilon=7124 \mathrm{~L} \mathrm{~mol}^{-1} \mathrm{~cm}^{-1}\right)$, $\lambda_{\max } 759 \mathrm{~nm}\left(\varepsilon=3997 \mathrm{~L} \mathrm{~mol}^{-1} \mathrm{~cm}^{-1}\right)$.

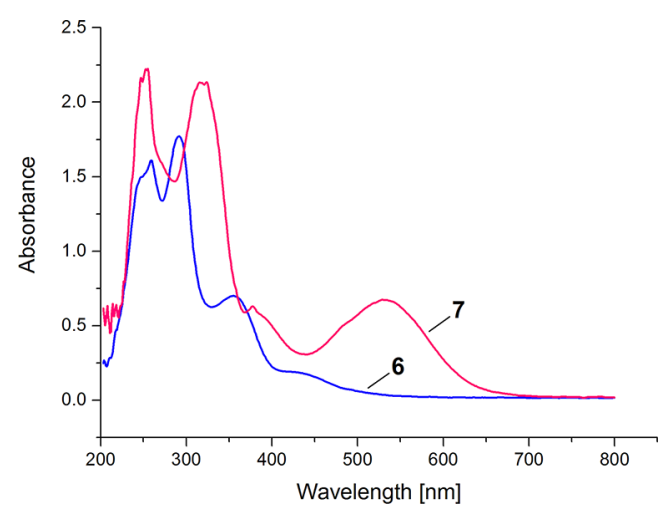

Figure 5. UV-vis spectra of azometallocenes. $6\left(\mathrm{CH}_{3} \mathrm{OH}\right): \lambda_{\max } 292$ $\mathrm{nm}\left(\varepsilon=13200 \mathrm{~L} \mathrm{~mol}^{-1} \mathrm{~cm}^{-1}\right), \lambda_{\max } 356 \mathrm{~nm}\left(\varepsilon=5220 \mathrm{~L} \mathrm{~mol}^{-1}\right.$ $\left.\mathrm{cm}^{-1}\right), \lambda_{\max } 427 \mathrm{~nm}\left(\varepsilon=1400 \mathrm{~L} \mathrm{~mol}^{-1} \mathrm{~cm}^{-1}\right) ; 7\left(\mathrm{CH}_{2} \mathrm{Cl}_{2}\right): \lambda_{\max } 321$ $\mathrm{nm}\left(\varepsilon=11200 \mathrm{~L} \mathrm{~mol}^{-1} \mathrm{~cm}^{-1}\right), \lambda_{\max } 378 \mathrm{~nm}\left(\varepsilon=2887 \mathrm{~L} \mathrm{~mol}^{-1}\right.$ $\left.\mathrm{cm}^{-1}\right), \lambda_{\max } 529 \mathrm{~nm}\left(\varepsilon=3084 \mathrm{~L} \mathrm{~mol}^{-1} \mathrm{~cm}^{-1}\right)$.

azoferrocene $^{8 c}$ analogue 7. As anticipated, donor-substituted ferrocenyl complexes 5 and 7 absorb at significantly higher wavelengths in comparison to acceptor-substituted cobaltoceniumyl compounds 4 and 6 (for an assignment of the underlying transitions see the following section). Interestingly, tetrazenido complexes $\mathbf{4}$ and $\mathbf{5}$ have comparable dye properties as chlorophylls with their distinctive Soret band at ca. $400 \mathrm{~nm}$ and their $Q$ bands ranging from 600 to $800 \mathrm{~nm}$.

Electrochemistry, UV/Vis/NIR Spectroelectrochemistry, and Quantum Chemistry. In the following, we discuss the electrochemical properties of the two azometallocene (or metallocenium) and the trinuclear tetrazenido complexes along with their electronic spectra in all experimentally accessible oxidation states. Assignments of the respective bands as based on experimental observations and (TD)DFT calculations are also provided. Electrochemistry data are collected in Table 1, whereas Table 2 compiles the data pertinent to the electronic spectra.

Table 2. UV/Vis/NIR Data for the Complexes in Charge State $n^{a}$

$\begin{array}{ccl}\text { complex } & \text { charge state } n & \lambda_{\max }(\mathrm{nm})\left(\varepsilon_{\max }\left(10^{-3} \mathrm{M}^{-1} \mathrm{~cm}^{-1}\right)\right) \\ 4^{a} & 2+ & 388(8.9), 526(8.3), 711(1.5) \\ & + & 476(8.4), 941(2.5) \\ & 0 & 440(6.6), 546(7.2), 1031(1.6) \\ 5^{b} & - & 452(8.69), 520(\mathrm{sh}), 780(3.1) \\ & 0 & 414(8.8), 463(8.8), 750(4.4) \\ \mathbf{6}^{a} & - & 345(13.5), 505(5.4) \\ & 2+ & 354(5.5), 429(\mathrm{sh}, 1.4) \\ & + & 465(2.2), 557(2.9), 1135(1.6) \\ 7^{c} & 0 & 423(\mathrm{sh}, 2.2), 569(5.8) \\ & 2+ & 361(\mathrm{sh}), 965(0.2) \\ & + & 358(9.6), 641(2.4), 1634(0.4) \\ & 0 & 321(11.2), 379(3.1), 530(3.1)\end{array}$

${ }^{a}$ In $\mathrm{CH}_{3} \mathrm{CN} / \mathrm{NBu}_{4}{ }^{+} \mathrm{PF}_{6}{ }^{-}(0.1 \mathrm{M}) .{ }^{b}$ In THF $/ \mathrm{NBu}_{4}{ }^{+} \mathrm{PF}_{6}{ }^{-}$(0.1 M). ${ }^{c}$ In $\mathrm{CH}_{2} \mathrm{Cl}_{2} / \mathrm{NBu}_{4}{ }^{+} \mathrm{PF}_{6}{ }^{-}(0.1 \mathrm{M})$.

The electrochemistry of azoferrocene 7 as well as the vis/ NIR spectroscopic characteristics of its mixed-valent radical cation have already been reported on earlier occasions. ${ }^{8 \mathrm{~d}, 12}$ Our own observations during the present study are in perfect agreement with these previous results, providing a pattern of two consecutive, reversible one-electron voltammetric waves with a significant half-wave potential splitting $\Delta E_{1 / 2}$ of $214 \mathrm{mV}$ and identical half-wave potentials despite the $\mathrm{NBu}_{4}^{+} \mathrm{PF}_{6}{ }^{-}$ supporting electrolyte being used instead of $\mathrm{NBu}_{4}{ }^{+} \mathrm{ClO}_{4}{ }^{-}$ (see Table 1 and Figure S19). ${ }^{8 \mathrm{~d}}$ We also confirmed the partial bleaching and red shift of the prominent metal to ligand charge-transfer (MLCT) band from 530 to $641 \mathrm{~nm}$ and the appearance of a weak intervalence charge-transfer band at 1634 $\mathrm{nm}$ on one-electron oxidation in a spectroelectrochemical setup (see Table 2 and Figure S20). ${ }^{13}$ The slightly different values of 672 and $1560 \mathrm{~nm}$ in ref $8 \mathrm{~d}$ might be due to an inflection of their spectra to negative values, which distorts the MLCT band, and the differences in the supporting electrolyte. Our setup also allowed us to monitor the spectroscopic changes concomitant with further oxidation of $7^{+}$to dication $7^{2+}$, which is accompanied by the bleaching of the IVCT and the vis bands (Figure S20). The vis band of $7^{+}$is therefore reassigned as a shifted MLCT instead of a LMCT (ligand to metal charge transfer) band, in contrast to the previous

Table 1. Cyclic Voltammetry Data of the Complexes ${ }^{a}$

\begin{tabular}{|c|c|c|c|c|}
\hline complex & $E_{1 / 2} \mathrm{Mc} / \mathrm{Mc}+(\mathrm{mV}), \mathrm{Mc}^{\mathrm{III}}-\mathrm{Co}-\mathrm{Mc}^{\mathrm{II} / \mathrm{III}}$ & $E_{1 / 2} \mathrm{Mc} / \mathrm{Mc}+(m V), \mathrm{Mc}^{\mathrm{II} / \mathrm{III}}-\mathrm{Co}-\mathrm{Mc}^{\mathrm{II}}$ & $E_{1 / 2}{ }^{\mathrm{CpCo}(\text { bridge })}(\mathrm{mV}), \mathrm{Mc}^{n+}-\mathrm{Co}^{\mathrm{III} / \mathrm{II}}-\mathrm{Mc}^{n+}$ & $\Delta E_{1 / 2}^{b}(\mathrm{mV})$ \\
\hline $4^{c}$ & -1585 & -1775 & -600 & $985 / 190$ \\
\hline $4^{d}$ & -1600 & -1840 & -675 & $925 / 240$ \\
\hline $\mathbf{5}^{d}$ & 23 & -66 & -1695 & $89 / 1629$ \\
\hline $5^{e}$ & 86 & -28 & -1660 & $114 / 1632$ \\
\hline $6^{c}$ & -600 & -890 & n.a. & 290 \\
\hline $7^{e}$ & 332 & 118 & n.a. & 214 \\
\hline
\end{tabular}

${ }^{a}$ All data in $\mathrm{mV}$ vs $\mathrm{Cp}_{2} \mathrm{Fe}^{0 /+}$ at $v=0.1 \mathrm{~V} / \mathrm{s} .{ }^{b} \mathrm{Half}-$ wave potential difference between two consecutive redox processes. ${ }^{c}$ In $\mathrm{CH}_{3} \mathrm{CN} / \mathrm{NBu}_{4}{ }^{+} \mathrm{PF}_{6}{ }^{-}(0.1$ M). ${ }^{d}$ In THF $/ \mathrm{NBu}_{4}{ }^{+} \mathrm{PF}_{6}{ }^{-}(0.1 \mathrm{M}) .{ }^{e} \mathrm{In}_{2} \mathrm{CH}_{2} \mathrm{Cl}_{2} / \mathrm{NBu}_{4}{ }^{+} \mathrm{PF}_{6}{ }^{-}(0.1 \mathrm{M})$. 
proposal (note that, in the case of an LMCT, this band would be expected to further red shift and increase in intensity on further oxidation as the number of ferrocenium electron acceptors doubles).

The electrochemical behavior of azocobaltocenium $\mathbf{6}$ is just a mirror image of that of 7 , showing two consecutive and likewise reversible one-electron reductions at -600 and -890 $\mathrm{mV}$ and an enhanced half-wave potential splitting of $290 \mathrm{mV}$ in comparison to its ferrocene congener (see Table 1 and Figure S21). The large anodic shifts of both waves in comparison to the cobaltocenium/cobaltocene $\left(\mathrm{Cc}^{+} / \mathrm{Cc}\right)$ redox couple $\left(E_{1 / 2}\right.$ $=-1330 \mathrm{mV})^{14}$ is a clear testimony to the strongly electron withdrawing character of the (acceptor-substituted) azo ligand. During the first reduction of dicationic 6 to its mixed-valent radical cation, we observe the growth of a considerably more intense IVCT band $\left(\mathrm{Cc}^{+} \rightarrow \mathrm{Cc}\right)$ at a much lower wavelength/ higher energy $\left(1135 \mathrm{~nm} / 8820 \mathrm{~cm}^{-1}\right)$ in comparison to that for the azoferrocene radical cation $\left(1634 \mathrm{~nm} / 6120 \mathrm{~cm}^{-1}\right)$ during the first reduction of dicationic 6 to its mixed-valent radical cation (Table 2 and Figure S22) in UV/vis/NIR spectroelectrochemical experiments. This is indicative of a stronger electronic coupling in the mixed-valent state. We also note the growth of a prominent vis absorption feature with a main peak at $557 \mathrm{~nm}$ and a smaller peak at $465 \mathrm{~nm}$ (Table 2). During the second reduction to neutral azocobaltocene (Figure S22 and Table 2), the absorptivity of this band further increases along with a slight red shift, while the IVCT band bleaches. This again argues for an MLCT character with charge transfer from the electron-rich $\mathrm{Cc}$ site(s) to the electron-accepting azo bridge, just as in azoferrocene.

As already mentioned, the tetrazenido ligand in the trinuclear complexes $\mathbf{4}$ and $\mathbf{5}$ is present in its dianionic state, thus providing a considerably more electron-rich connector as opposed to the neutral azo bridge in complexes 6 and 7. As a consequence, the three reversible one-electron reduction waves of 4 at $-600,-1585$, and $-1775 \mathrm{mV}$ (see Figure 6) are

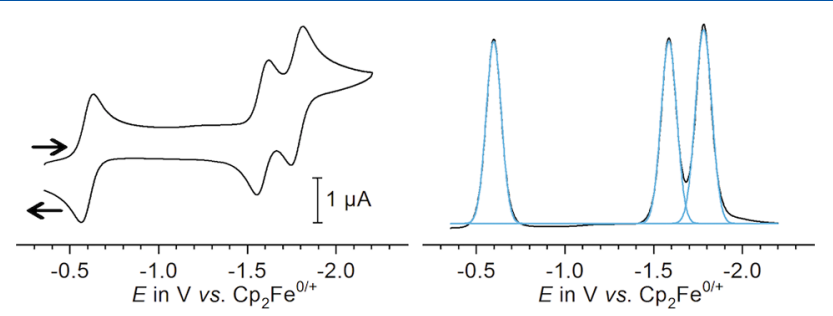

Figure 6. Cyclic (left) and square-wave voltammogram (right) of complex 4 in $\mathrm{CH}_{3} \mathrm{CN} / 0.1 \mathrm{M} \mathrm{NBu}_{4}{ }^{+} \mathrm{PF}_{6}{ }^{-}(v=0.1 \mathrm{~V} / \mathrm{s}$ or square-wave frequency $50 \mathrm{~Hz}$, step height $2 \mathrm{mV}$, at room temperature).

assigned to the stepwise reductions of first the central $\mathrm{CpCo}{ }^{\mathrm{III}}$ (tetrazenido) fragment and then the individual $\mathrm{Cc}^{+}$ entities. Thus, replacing the azo bridge of $6\left(d_{\mathrm{Co} \cdots \mathrm{Co}}=6.611 \AA\right)$ by the more extended $\mathrm{CpCo}^{\mathrm{II}}$-1,4-tetrazenido bridge $\left(d_{\mathrm{Co} \cdots \mathrm{Co}}=\right.$ $7.682 \AA$ ), which is present after the first reduction of 4 , decreases $\Delta E_{1 / 2}$ from 290 to $190 \mathrm{mV}$.

That assignment of redox events is further supported by our quantum chemical calculations, which place the LUMO almost exclusively on the $\mathrm{CpCo}$ (tetrazenido) fragment of 4 (for a compilation of relevant frontier MOs see Figure S23). Consequently, all three vis bands in the electronic spectrum of $\mathbf{4}$ are assigned as LMCT from occupied, ligand-based MOs, spread over mainly the tetrazenido bridge with lesser contributions from the attached $\mathrm{Cp}$ rings, to the central
$\mathrm{CpCo}^{\mathrm{III}}$ fragment. Figure 7 (top) provides graphical accounts of the charge density differences concomitant with the
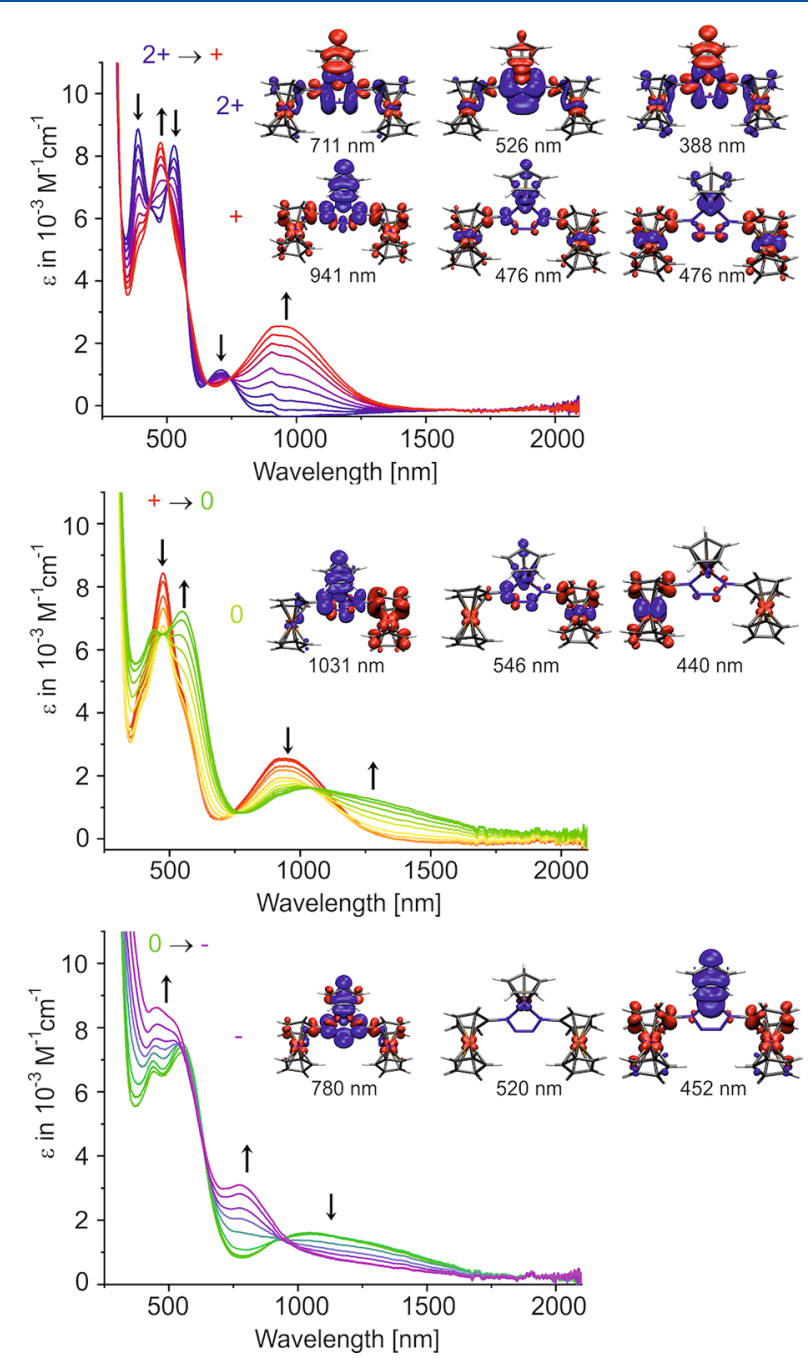

Figure 7. Changes in the UV/vis/NIR spectra on stepwise reduction of complex 4 to the radical cation (top), the neutral state (middle), and the anion (bottom) $\left(\mathrm{CH}_{3} \mathrm{CN} / 0.1 \mathrm{M} \mathrm{NBu}_{4}{ }^{+} \mathrm{PF}_{6}{ }^{-}\right.$, room temperature) and charge density different plots for the individual transitions with the corresponding experimental wavelengths. The blue color indicates a loss and the red color a gain of electron density.

individual absorptions of 4, while Figure S24 demonstrates the good match between the computed and the experimental spectra.

As is shown in Figure 7 (top), the first one-electron reduction causes the bleaching of the least intense vis absorption at $711 \mathrm{~nm}$ and the growth of a much stronger band at an even lower energy $\left(\lambda_{\max } 941 \mathrm{~nm}, 10640 \mathrm{~cm}^{-1}\right)$ and merges the two more intense vis bands into an equally intense, composite band at an intermediate position (Table 2). With reference to our quantum chemical calculations, the transition underlying the low-energy band can be assigned as metal to metal charge transfer (MMCT) from the $\mathrm{CpCo}^{\mathrm{II}}$ entity to the appended $\mathrm{Cc}^{+}$sites, while the absorptions at higher energies have more of an MLCT origin with charge transfer from the same donor moiety to the central azo unit of the tetrazenido bridge and mainly the ipso atoms of the $\mathrm{Cc}^{+} \mathrm{Cp}$ ligands. Charge density difference plots for these transitions are also 
provided in Figure 7, while Figure S26 compares the experimental and computed spectra.

During the second reduction of 4 (Figure 7, middle), the intensity of the NIR band diminishes somewhat along with a red shift by $930 \mathrm{~cm}^{-1}$ to $1031 \mathrm{~nm}$ (Table 2). Moreover, the prominent vis absorption splits into two separate bands at higher and lower energies. According to our quantum chemical calculations, doubly reduced $4^{2-}$ has a triplet ground state. The principal character of the NIR band as MMCT from the central $\mathrm{CpCo}^{\mathrm{II}}$ (tetrazenido) fragment to the remaining $\mathrm{Cc}^{+}$ site is retained with hardly any admixture of intervalence charge transfer (IVCT) from reduced $\mathrm{Cc}$ to $\mathrm{Cc}^{+}$. The vis bands are more mixed in character with, again, MMCT between $\mathrm{CpCo}^{\mathrm{II}}$ (tetrazenido) and $\mathrm{Cc}^{+}$, augmented by MLCT at the $\mathrm{Cc}^{+}$ entity or have dominant MLCT within the Cc unit (see Figure 7, middle; for a comparison of computed and experimental spectra see Figure S27).

Triply reduced $4^{3-}$ has three paramagnetic $\mathrm{Co}^{\mathrm{II}}$ centers and, according to our calculations, a quartet ground state where all three spins are aligned parallel. Our calculations assign the remaining vis absorptions at 780, 520, and $452 \mathrm{~nm}$ (see Figure 7 , bottom) as charge transfer from the central $\mathrm{CpCo}^{\mathrm{II}}$ (tetrazenido) to the $\mathrm{Cc}$ units.

Cyclic and square wave voltammograms of complex $\mathbf{5}$ as represented by Figure 8 show two closely spaced one-electron
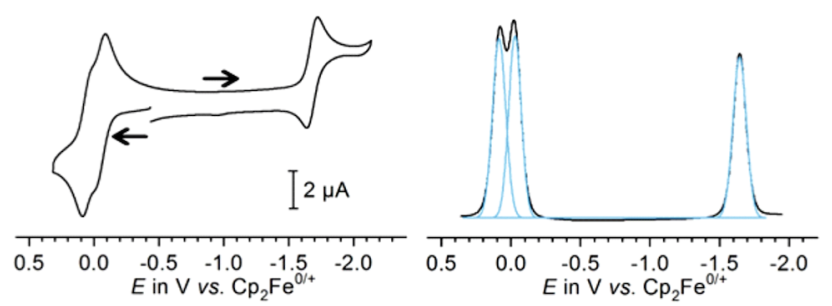

Figure 8. Cyclic (left) and square-wave voltammogram (right) of complex 5 in $\mathrm{CH}_{3} \mathrm{CN} / 0.1 \mathrm{M} \mathrm{NBu}_{4}{ }^{+} \mathrm{PF}_{6}{ }^{-}(v=0.1 \mathrm{~V} / \mathrm{s}$ or square-wave frequency $50 \mathrm{~Hz}$, step height $2 \mathrm{mV}$, at room temperature).

waves for the stepwise oxidation of the peripherally appended ferrocenyl substituents and a reduction of the central $\mathrm{CpCo}^{\mathrm{III}}$ (tetrazenido) unit. As was found for the comparison of azaferrocene 7 and azacobaltocenium 6 , the half-wave potential splitting for stepwise oxidation of the ferrocene sites is substantially smaller than that observed for its cobaltocenium analogue. In $\mathbf{5}$, these two oxidations are merged into one composite wave or peak, and half-wave potential splitting as estimated from deconvolution of the square-wave peak is down to $89 \mathrm{mV}$ in $\mathrm{THF} / \mathrm{NBu}_{4}{ }^{+} \mathrm{PF}_{6}{ }^{-}$or $114 \mathrm{mV}$ in $\mathrm{CH}_{2} \mathrm{Cl}_{2}$ / $\mathrm{NBu}_{4}{ }^{+} \mathrm{PF}_{6}{ }^{-}$, in comparison to $190 \mathrm{mV}$ in 4 (see Figure 8 and Figure S28). Replacing the cationic $\mathrm{Cc}^{+}$appendants by neutral ferrocenes shifts the reduction potential of the $\mathrm{CpCo}^{\mathrm{III}}$ (tetrazenido) entity by almost $1100 \mathrm{mV}$, to -1660 $\left(\mathrm{CH}_{2} \mathrm{Cl}_{2}\right)$ or $-1700 \mathrm{mV}$ (THF). This provides clear evidence of how strongly the appended metallocene/metallocenium entities influence the electronic properties of the tetrazenido bridge and, thus, the entire trinuclear arrays. In $\mathrm{CH}_{2} \mathrm{Cl}_{2}$, the reduction of $\mathbf{4}$ is followed by a chemical step which consumes the reduced form at the expense of a new species, which itself is being reduced at a peak potential of $-1.90 \mathrm{~V}$ (see Figure S28 for a representative $\mathrm{CV}$ ). That process is outrun at sweep rates of $400 \mathrm{mV} / \mathrm{s}$ or faster. No such complications were encountered in THF, where reduced 4 proved stable on the time scale of the voltammetric and of the spectroelectrochemical experiments.

Figure 9 collects the UV/vis/NIR spectra of complex 5 in its neutral and monanionic states along with the charge density

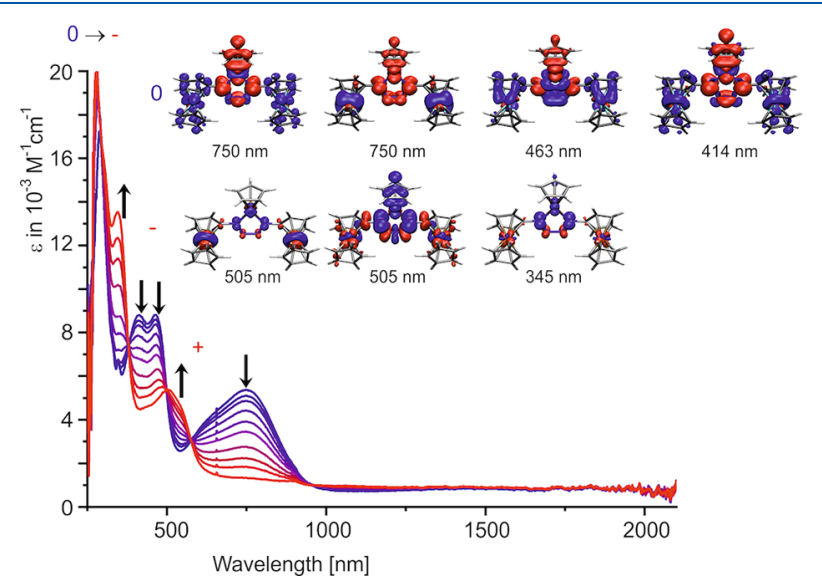

Figure 9. Changes in the UV/vis/NIR spectra on stepwise reduction of complex 5 to the radical anion (THF/0.1 $\mathrm{M} \mathrm{NBu}_{4}{ }^{+} \mathrm{PF}_{6}{ }^{-}$, room temperature) and charge density different plots for the relevant transitions with the corresponding experimental wavelengths. The blue color indicates loss and the red color gain of electron density.

difference plots for the transitions at the lowest energies. Phenomenologically, the electronic spectrum of $\mathbf{5}$ resembles that of singly reduced $4^{-}$(compare Figure 7 and Figure 9 and see Table 2), but with inverted donor/acceptor roles of the peripheral and central sites. Thus, while charge transfer in singly reduced $4^{-}$occurs from the central $\mathrm{CpCo}^{\mathrm{II}}$ unit to the appended $\mathrm{Cc}^{+}$acceptors, it is directed from the outer $\mathrm{Fc}$ donors to the inner $\mathrm{CpCo}^{\mathrm{III}}$ acceptor in $\mathbf{5}$ (for further charge density difference plots see Figure S29). We again note an excellent match between computed and experimental spectra (as documented in Figure S30). In the same vein, the spectrum and the nature of the electronic transitions of reduced $5^{-}$ resemble those of triply reduced $4^{3-}$, which is also present as a monoanion with three metal ions in oxidation state $2+$. Unfortunately, oxidized $\mathbf{5}$ proved to be unstable on the time scale of the spectroelectrochemical experiment in any solvent we tried, and no data can therefore be presented.

Catalytic Studies. The electrocatalytic proton reduction activity of $\mathbf{4}$ was probed in acetonitrile using acetic acid as the proton source $\left(\mathrm{p} K_{\mathrm{a}}^{\mathrm{MeCN}}=22.3\right)$. Since the reduction potential for generating doubly reduced $4^{2-}$ or fully reduced $4^{3-}$ is more negative than the standard reduction potential of acetic acid in acetonitrile $(-1.39 \mathrm{~V})$, such electrocatalysis is thermodynamically possible. ${ }^{15}$ Upon sequential additions of acetic acid (from 5 to $200 \mathrm{mM}$ ), the two reversible reduction processes for the $\mathrm{Cc}^{+}$units coalesce to a single irreversible wave at $-1.65 \mathrm{~V}$ with an $\sim 12$-fold increase in peak current, $i_{\mathrm{p}}$ (Figure 10A). To investigate this proton-responsive behavior, we recorded cyclic voltammograms of $\mathbf{4}$ with smaller increments of acetic acid (Figure S31). In the presence of low concentrations of acid $(0-5 \mathrm{mM})$, the reduction wave at $-1.78 \mathrm{~V}$ was rendered irreversible and the peak current was enhanced by $\sim 2.7$-fold before plateauing at $\sim 5 \mathrm{mM}$ acetic acid (Figure 10B). At higher acid concentration $(>5 \mathrm{mM})$, the peak at $-1.58 \mathrm{~V}$ started to grow, and above $50 \mathrm{mM}$, the two peaks eventually merged into a single reductive wave which continued to grow with increasing acid concentration. Emergence of one 

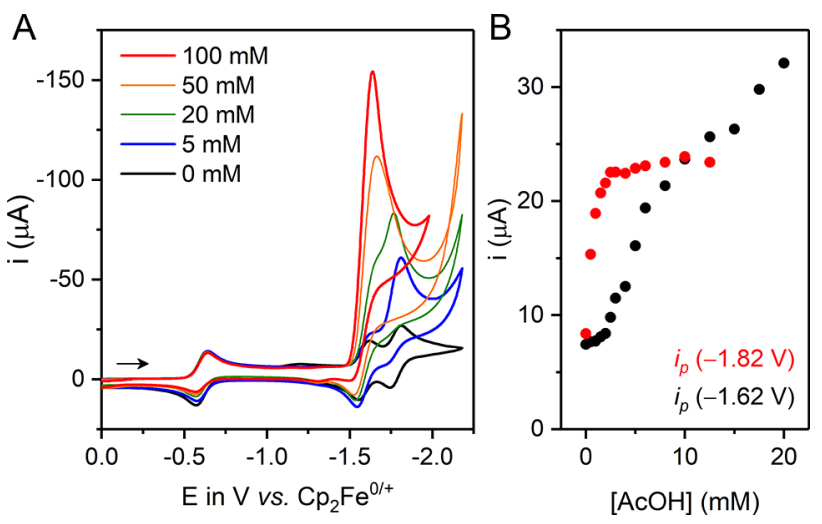

Figure 10. (A) Cyclic voltammograms of $4(0.5 \mathrm{mM})$ with various concentrations of acetic acid recorded in $0.1 \mathrm{M} \mathrm{NBu}_{4}{ }^{+} \mathrm{PF}_{6}{ }^{-} /$ acetonitrile at a potential scan rate of $0.1 \mathrm{~V} \mathrm{~s}^{-1}$. (B) Dependence of the reductive peak currents at $-1.62 \mathrm{~V}$ (black) and $-1.82 \mathrm{~V}$ (red) on the concentration of acetic acid.

reductive wave at higher acid concentration suggests that protonation of the tetrazenido ligand disrupts the electronic communication between the two appended $\mathrm{Cc}^{+}$units, leading to smaller half-wave potential splitting. However, it should be noted that the tetrazenido ligand in $\mathbf{4}$ does not undergo protonation by acetic acid at the resting state, as the first reduction wave at $-0.6 \mathrm{~V}$ remained unaffected in acidic condition. Foot-of-the-wave analysis (FOWA) of the cyclic voltammograms was carried out to acquire kinetic information on the catalytic process. The overall rate constant for $\mathrm{H}_{2}$ evolution $\left(k_{\mathrm{obs}}\right)$, which equals the maximum turnover frequency $\left(\mathrm{TOF}_{\max }\right.$ ), was estimated to be $46.1 \pm 0.3$ and $59.5 \pm 0.5 \mathrm{~s}^{-1}$ in the presence of 0.05 and $0.10 \mathrm{M}$ acetic acid, respectively (Figure S32A). ${ }^{16}$ Notably, 4 shows a relatively early onset potential for electrocatalytic reduction of acetic acid, which is illustrated by the catalytic Tafel plot (Figure S32B). Approximately $300 \mathrm{mV}$ overpotential was required to achieve maximum turnover frequency.

Controlled-potential electrolysis was performed at $-1.75 \mathrm{~V}$ in the presence of $0.2 \mathrm{M}$ acetic acid to verify that the current enhancement at $-1.65 \mathrm{~V}$ is caused by electrocatalytic proton reduction (Figure S33). Evolution of hydrogen gas was confirmed by gas chromatographic (GC) analysis, and the Faradaic efficiency of $\mathrm{H}_{2}$ formation was estimated to be $80( \pm 5) \%$. One hour of electrolysis at $350 \mathrm{mV}$ overpotential ( $\eta$ ) using $1.4 \mu \mathrm{mol}$ of 4 generated $4.1 \mu \mathrm{mol}$ of $\mathrm{H}_{2}$, which corresponds to a turnover number (TON) of 2.9 per catalyst molecule in the electrolyte solution. Electrolysis over a longer time period $(2 \mathrm{~h})$ led to lower Faradaic efficiency for $\mathrm{H}_{2}$ evolution, suggesting degradation of the catalyst.

The catalytic peak current increases linearly with the concentration of 4 , consistent with a mechanism for $\mathrm{H}_{2}$ evolution that is first order in catalyst (Figure S34). Emergence of the catalytic wave at the $\mathrm{Cc}^{+} / \mathrm{Cc}$ reduction potential hints that the central tetrazenido ligand may act as a proton shuttle to the central cobalt center, the likely site for electrocatalysis. Reduction of $\mathrm{Cc}^{+}$units enhances the electron density around the tetrazenido ligand and facilitates its protonation. A mechanism can be tentatively proposed that subsequently involves proton transfer and reduction to generate a cobalthydride intermediate species, which undergoes protonation to form molecular hydrogen (Scheme S1).
On the other hand, voltammograms of 5 were unaffected by addition of acetic acid, which shows that the singly reduced $\mathrm{CpCo}{ }^{\mathrm{II}}$-tetrazenido fragement is not sufficiently basic to bind a proton and mediate electrochemical $\mathrm{H}_{2}$ evolution. This further emphasizes the influential role played by the appended metallocene units in modulating the electrochemical property of the central cobalt-tetrazenido moiety.

The cyclic voltammogram of 6 in the presence of acetic acid consists of two reversible peaks at -0.60 and $-1.56 \mathrm{~V}$ (Figure 11 ). The peak currents for these two processes were double

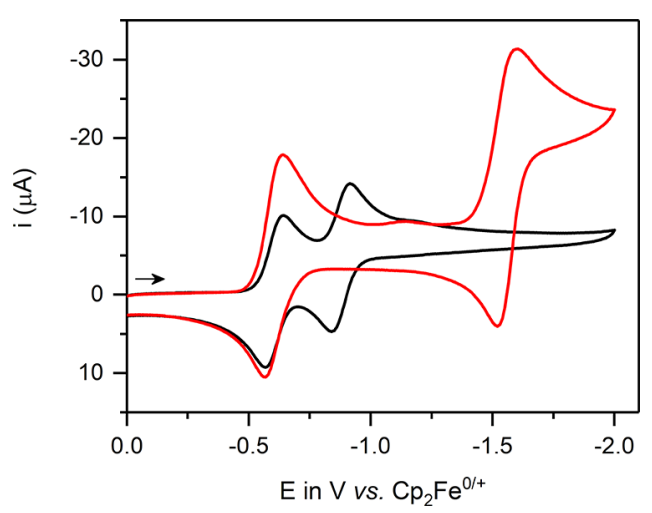

Figure 11. Cyclic voltammograms of $6(0.5 \mathrm{mM})$ recorded in $0.1 \mathrm{M}$ $\left[\mathrm{NBu}_{4}\right]\left[\mathrm{PF}_{6}\right] /$ acetonitrile at a potential scan rate of $0.1 \mathrm{~V} \mathrm{~s}^{-1}$ in the absence (black trace) and in the presence of $1 \mathrm{mM}$ acetic acid (red trace).

that observed for the one-electron reductions of 6 at -0.6 and $-0.89 \mathrm{~V}$ in the absence of acid, which indicates that the new peaks correspond to two-electron processes. However, no further increase in peak current was observed upon addition of excess acetic acid, suggesting that $\mathbf{6}$ is not an electrocatayst under these conditions. Interestingly, the half-wave potential $\left(E_{1 / 2}\right)$ of the first reduction process at $-0.6 \mathrm{~V}$ shows an incremental anodic shift with increasing acid concentration, which suggests a proton-coupled electron transfer (PCET) process (Figure S36). The redox processes could be tentatively assigned to the reduction of the two $\mathrm{Cc}^{+}$centers and $2 \mathrm{e}^{-}$ reduction of the azo linkage. In contrast, $\mathrm{CVs}$ of 7 display no such proton-responsive behavior (Figure S37).

\section{CONCLUSION}

The first trimetallic tetrazenido complexes containing peripheral metallocenyl substituents of opposite donor/acceptor character have been prepared from cobaltoceniumyl- and ferrocenylazide, respectively, and (cyclooctadiene)(cyclopentadienyl)cobalt(I). These highly colored, conjugated, and redox-responsive complexes were fully characterized by NMR, IR, MS, UV/vis, and X-ray diffraction. The redoxnoninnocent tetrazenido ligand is present in its dianionic form, thereby assigning redox state $3+$ to the central cobalt atom. Detailed spectroelectrochemical studies in combination with DFT calculations allowed a precise assignment of electronic transitions depending on the charge/redox state of the complexes. The dicationic, highly stable, and polar dicobaltoceniumyl-tetrazenido-CpCo complex catalyzes electrochemical proton reduction in acidic solution at a modest overpotential. Furthermore, these tetrazenido complexes were compared in their properties to their related diazenes "azoferrocene" and "azocobaltocenium bis(hexafluoridophosphate)", respectively. 


\section{EXPERIMENTAL SECTION}

General Considerations. Standard methods and procedures of organometallic synthesis were applied. Chemicals were obtained commercially and used as received. Solvents were dried, degassed, and distilled before usage. Starting materials azidocobaltocenium hexafluoridophosphate $(\mathbf{1}),{ }^{3}$ cyclooctadiene(cyclopentadienyl) cobalt $(\mathrm{I})^{6}$ (3) and aminocobaltocenium hexafluoridophosphate ${ }^{3}$ (8) were synthesized according to literature procedures. Spectroscopic characterization methods and single-crystal structure analysis were performed as detailed recently..$^{10 a}$

Cyclic Voltammetry. Cyclic voltammetry was performed in a one-compartment cell with 5-7 $\mathrm{mL}$ of the respective solvent and $\mathrm{NBu}_{4} \mathrm{PF}_{6}(0.1 \mathrm{M})$ as the supporting electrolyte. A platinum electrode $(\varnothing=1.1 \mathrm{~mm}, \mathrm{BASI})$ was used as the working electrode. It was polished with diamond pastes ( 1.5 and $1 \mu \mathrm{m}$ particle size) from Buehler\&Wirtz. A computer-controlled BASi EPSILON potentiostat was used for recording of the voltammograms. $\mathrm{An} \mathrm{Ag} / \mathrm{AgCl}$ wire pseudo reference electrode and a Pt wire as an auxiliary electrode were used in the measurements. The cell was connected to an argon gas bottle. Potential calibration was performed by adding appropriate quantities of decamethylferrocene $\left(\mathrm{Cp}^{*}{ }_{2} \mathrm{Fe}\right)$ or $\mathrm{Cc}^{+} \mathrm{PF}_{6}^{-}$after all scans of interest had been acquired. Potentials are reported against the ferrocene/ferrocenium $\left(\mathrm{Cp}_{2} \mathrm{Fe}^{0 /+}\right)$ couple, which is $550 \mathrm{mV}$ positive of the $\mathrm{Cp}^{*}{ }_{2} \mathrm{Fe}^{0 /+}$ couple and $1330 \mathrm{mV}$ positive of the $\mathrm{Cc}^{+} / \mathrm{Cc}$ couple under our conditions.

IR and UV/Vis/NIR Spectroelectrochemistry. IR and UV/vis/ NIR spectroelectrochemistry was performed in a self-built optically transparent thin-layer electrolysis (OTTLE) cell according to the design of Hartl. ${ }^{13}$ A platinum minigrid as the working and counter electrodes and a thin silver foil as reference electrode were welded in a polyethylene spacer, incorporated into a Teflon housing with electrical connectors, and sandwiched between the $\mathrm{CaF}_{2}$ plates of a conventional liquid IR cell. 1,2- $\mathrm{C}_{2} \mathrm{H}_{4} \mathrm{Cl}_{2} / 0.1 \mathrm{M} \mathrm{NBu}_{4} \mathrm{PF}_{6}$ was used as the supporting electrolyte. IR/NIR spectra were recorded on a FT-IR Bruker Tensor II instrument. The UV/vis/NIR measurements were performed on a TIDAS diode array unit by j\&m ANALYTIK AG with a spectroscopic window of $250-2100 \mathrm{~nm}$. A WENKING POS3 computer-controlled potentiostat was used for controlled-potential electrolysis.

Density Functional Theory (DFT) Calculations. These calculations were performed on the full model complexes using the GAUSSIAN 09 program package. ${ }^{17}$ Geometry optimizations were performed without any symmetry constraints. Electronic transitions were calculated by the time-dependent DFT (TD-DFT) method. Within G09 calculations the quasi-relativistic effective core pseudopotentials and the corresponding optimized set of basis functions for $\mathrm{Ru}$ were used. ${ }^{18}$ Polarized double- $\zeta$ basis sets (6$31 \mathrm{G}(\mathrm{d})$, geometry optimization) were employed together with the pbelpbe functional. ${ }^{19}$ Solvation effects were modeled by the polarizable continuum model $(\mathrm{PCM})^{20}$ in TD-DFT calculations.

Catalytic Studies. Cyclic voltammetry was performed on a PalmSens EmStat potentiostat using a conventional three-electrode setup with a glassy-carbon working electrode ( $3 \mathrm{~mm}$ diameter), Ptwire counter electrode, and a $\mathrm{Ag} / \mathrm{AgCl} / \mathrm{KCl}$ (saturated) reference electrode. A $0.1 \mathrm{M}$ solution of $\mathrm{NBu}_{4}{ }^{+} \mathrm{PF}_{6}{ }^{-}$in $\mathrm{MeCN}$ was used as supporting electrolyte. Bulk electrolyses were carried out in a twocompartment $\mathrm{H}$ cell connected by a glass frit using a Bio-Logic science multichannel potentiostat. A glassy-carbon rod with a surface area of $\sim 0.2 \mathrm{~cm}^{2}$ was used as a working electrode, and platinum mesh as a counter electrode. Prior to electrolysis, the electrolyte solution was deaerated by sparging $\mathrm{N}_{2}$, and then the electrochemical cell was kept closed and gastight during the electrolysis. Typically, the volume of electrolyte in the working compartment was $6 \mathrm{~mL}$, and that in the counter compartment was $4 \mathrm{~mL} . \mathrm{H}_{2}$ produced during electrolyses was quantified with a Shimadzu Tracera GC-2010 Plus gas chromatograph kept at $130{ }^{\circ} \mathrm{C}$ equipped with a barrier ionization discharge (BID) detector and a molecular sieve column with $\mathrm{He}$ as the carrier gas. Methane $\left(2 \% \mathrm{CH}_{4}\right.$ in $\left.\mathrm{N}_{2}\right)$ was used as internal standard.
Azidoferrocene (2): ${ }^{4}$ Improved Synthesis. A $50 \mathrm{~mL}$ Schlenk vessel was charged with $22 \mathrm{~mL}$ of dry, deoxygenated ethanol and $1.000 \mathrm{~g}$ of bromoferrocene ( $3.775 \mathrm{mmol}, 1.0$ equiv). The mixture was cooled with stirring in an ice bath, and $0.482 \mathrm{~g}$ of anhydrous $\mathrm{CuCl}$ (4.869 mmol, 1.3 equiv) was added under protection of light. In a separate vessel, $0.550 \mathrm{~g}$ of $\mathrm{NaN}_{3}(8.460 \mathrm{mmol}, 2.2$ equiv) was dissolved in $1.6 \mathrm{~mL}$ of Ar-saturated water. An aqueous solution of $\mathrm{NaN}_{3}$ was added to the solution of bromoferrocene and $\mathrm{CuCl}$, the mixture was sonicated at $0{ }^{\circ} \mathrm{C}$ for $3 \mathrm{~h}$ under protection of light, and stirring was continued in the dark overnight at $0{ }^{\circ} \mathrm{C}$. Workup was performed under ambient conditions. The orange-brown reaction mixture, containing mostly yellow-white $\mathrm{CuBr}$ with some green copper residues, was filtered through a short column of Celite to remove the copper salts, and the column was washed with five portions of ethanol, giving an orange-brown solution of the crude product. The solvent was reduced in volume on a rotary evaporator to $\sim 5 \mathrm{~mL}$, and $60 \mathrm{~mL}$ of water was added to dissolve excess $\mathrm{NaN}_{3}$ and to achieve better phase separation in the following liquid-liquid extraction with three to five $150 \mathrm{~mL}$ portions of diethyl ether. The orange-yellow organic phases were combined and washed with two $100 \mathrm{~mL}$ portions of cold water followed by one $50 \mathrm{~mL}$ portion of saturated aqueous $\mathrm{NaCl}$ solution. The organic phase was dried over $\mathrm{Na}_{2} \mathrm{SO}_{4}$, and the solvent was stripped off on a rotary evaporator, giving an orange-brown oil of the pure product. This material was kept in the refrigerator overnight under an atmosphere of Ar. On opening of the flask in the next morning, the oil solidified spontaneously, affording $0.759 \mathrm{~g}$ of yellow-brown 2 (3.343 mmol, $89 \%$ yield; reported yield ${ }^{4 \mathrm{~b}}$ in the literature $69 \%$ ) as a highly crystalline material. Spectral data concur with published values. ${ }^{4 b}$ Azidoferrocene (2) is slightly light sensitive in solution and should be stored under protection of light at low temperature.

Dicobaltoceniumyl-Tetrazenido Complex (4). A quartz Schlenk tube was charged with $20 \mathrm{~mL}$ of 1,2-dichloroethane under protection from air by an argon atmosphere and cooled to $-35^{\circ} \mathrm{C}$. A $0.080 \mathrm{~g}$ portion of azidocobaltocenium hexafluoridophosphate (1; $0.213 \mathrm{mmol}, 2.0$ equiv) and $0.025 \mathrm{~g}$ of freshly prepared (1,5cyclooctadiene $)$ (cyclopentadienyl)cobalt $(\mathrm{I})^{6} \quad(3 ; 0.107 \mathrm{mmol}, 1.0$ equiv) were added, and the reaction mixture was irradiated with a $700 \mathrm{~W}$ high-pressure water-cooled mercury lamp for $6 \mathrm{~h}$. A dark redbrown product mixture was obtained, containing yellow-brown aminocobaltocenium hexafluoridophosphate ${ }^{3}$ and orange azocobaltocenium bis(hexafluoridophosphate) (6) as byproducts, as well as intense red product 4 . The reaction mixture was placed in a freezer and cooled to $-20{ }^{\circ} \mathrm{C}$ for $2 \mathrm{~h}$. The black-red solid was filtered off on a Büchner funnel and thoroughly washed three times with diethyl ether, the receiving flask was replaced, and the fine powdery product was diluted with acetonitrile. Note: theoretical yield at this stage by NMR analysis is approximately $90 \%$, with $6 \%$ of aminocobaltocenium hexafluoridophosphate (8) and $1 \%$ of azocobaltocenium bis(hexafluoridophosphate) (6) as byproducts. Purification was achieved via diffusion crystallization in acetonitrile out of diethyl ether overnight at room temperature concomitant with significant yield losses. Product $\mathbf{4}$ crystallized as black-red needles and was filtered off on a Büchner funnel. Only the needles were collected, and the powder in the pores was discarded. Note: the powder in the pores can only be gained by dissolution with acetonitrile and still contains $\sim 1 \%$ of the azocobaltocenium bis(hexafluoridophosphate) (6) byproduct. Drying in vacuo afforded $0.051 \mathrm{~g}(0.060 \mathrm{mmol})$ of 4 , representing a yield of $57 \%$. Compound 4 is intensely red and highly air, heat, and water stable. It dissolves well in acetonitrile, acetone, and dimethyl sulfoxide, moderately well in methanol and water, and slightly in 1,2dichloroethane and dichloromethane. ${ }^{1} \mathrm{H}$ NMR $(300 \mathrm{MHz}$, $\left.\mathrm{CD}_{3} \mathrm{CN}\right): \delta 5.49$ (s, 5H, Co-Cp), 5.61 (s, 10H, Cc-Cp), 5.84 (pseudo-t, $4 \mathrm{H}, J=2.1 \mathrm{~Hz}, \mathrm{C} 3 / \mathrm{C} 4$ of substituted $\mathrm{Cc}-\mathrm{Cp}$ ), 6.60 (pseudo-t, $4 \mathrm{H}, J=2.3 \mathrm{~Hz}, \mathrm{C} 2 / \mathrm{C} 5$ of substituted $\mathrm{Cc}-\mathrm{Cp}$ ) ppm. ${ }^{13} \mathrm{C}$ NMR $\left(75 \mathrm{MHz}, \mathrm{CD}_{3} \mathrm{CN}\right): \delta 79.1(\mathrm{C} 3 / \mathrm{C} 4$ of substituted $\mathrm{Cc}-\mathrm{Cp})$ 81.1 (Co-Cp), 82.9 (C2/C5 of substituted Cc-Cp), 129.0 (quart. carbon of substituted $\mathrm{Cc}-\mathrm{Cp}$ ) ppm. MS (MALDI pos, $[\mathrm{m} / z]): 700.96$ $\left[\mathrm{M}-\mathrm{PF}_{6}{ }^{-}\right]^{+}$. IR (ATR): $3125\left(\nu_{\mathrm{C}-\mathrm{H}}\right), 2927\left(\nu_{\mathrm{C}-\mathrm{H}}\right), 1726,1462$ $\left(\nu_{\mathrm{C}=\mathrm{C}}\right), 1420\left(\nu_{\mathrm{C}=\mathrm{C}}\right), 1260,1031,814\left(\nu_{\mathrm{P}-\mathrm{F}}\right), 554\left(\nu_{\mathrm{P}-\mathrm{F}}\right), 515,470$ 
$\left(\nu_{\text {as }(\text { Co-ring })}\right) \mathrm{cm}^{-1}$. UV/vis $\left(\mathrm{CH}_{3} \mathrm{CN}\right): \lambda_{\max } 388 \mathrm{~nm}\left(\varepsilon=8865 \mathrm{~L} \mathrm{~mol}^{-1}\right.$ $\left.\mathrm{cm}^{-1}\right), \lambda_{\max } 528 \mathrm{~nm}\left(\varepsilon=8805 \mathrm{~L} \mathrm{~mol}^{-1} \mathrm{~cm}^{-1}\right), \lambda_{\max } 706 \mathrm{~nm}(\varepsilon=1551$ $\left.\mathrm{L} \mathrm{mol}^{-1} \mathrm{~cm}^{-1}\right)$. Complex 4 crystallizes readily via diffusion crystallization in acetonitrile out of diethyl ether overnight at room temperature, and single crystals were obtained in an analogous manner: $\mathrm{mp}>300{ }^{\circ} \mathrm{C}$. Spectra and crystallographic data are given in the Supporting Information.

Diferrocenyl-Tetrazenido Complex (5) and Azoferrocene (7). A $50 \mathrm{~mL}$ round-bottom Schlenk flask equipped with a reflux condenser was charged with $15 \mathrm{~mL}$ of 1,2-dichloroethane, $0.200 \mathrm{~g}$ of azidoferrocene $2(0.881 \mathrm{mmol}, 2.0$ equiv), and $0.102 \mathrm{~g}$ of freshly prepared (1,5-cyclooctadiene) (cyclopentadienyl)cobalt $(\mathrm{I})^{6}$ (3; 0.440 mmol, 1.0 equiv) under protection from air by an argon atmosphere. After the mixture was refluxed overnight, a dark solution was obtained, containing black byproduct, pink azoferrocene 7 , and green product 5. The reaction mixture was cooled to a heating bath temperature of $40{ }^{\circ} \mathrm{C}$, and the solvent was removed in vacuo. Note: unreacted (1,5-cyclooctadiene)(cyclopentadienyl)cobalt(I) sublimes under these conditions and can thus be removed. For purification the reaction mixture was dissolved in $5 \mathrm{~mL}$ of dichloromethane and applied on a previously conditioned neutral aluminum oxide column (solvent: pentane/diethyl ether, v/v 3/2). Chromatographic details: $400 \mathrm{~mL}$ of solvent 1 (pentane/diethyl ether, $\mathrm{v} / \mathrm{v} \mathrm{3/2}$ ) to remove remaining (1,5-cyclooctadiene)(cyclopentadienyl)cobalt(I) (3), 300 $\mathrm{mL}$ of solvent 2 (pentane/diethyl ether, $\mathrm{v} / \mathrm{v} 1 / 1$ ) to enhance separation, $500 \mathrm{~mL}$ of solvent 3 (diethyl ether) to elute pink azoferrocene $7,100 \mathrm{~mL}$ of solvent 4 (acetonitrile/diethyl ether, v/v 1/ 1) for washing, $500 \mathrm{~mL}$ of solvent 5 (acetonitrile) to elute green product 5. Note: the amount of dry, pink azoferrocene 7 was $0.026 \mathrm{~g}$ $(0.065 \mathrm{mmol}), 15 \%$ yield. Spectroscopic data of 7 concur with published values. ${ }^{8 c}$ The green acetonitrile fraction was collected, and the solvent was removed on a rotary evaporator. Drying in vacuo afforded $0.053 \mathrm{~g}(0.096 \mathrm{mmol})$ of green powdery 5 , representing a yield of $22 \%$. Compound 5 is slightly light as well as air sensitive. It dissolves well in dichloromethane, 1,2-dichloroethane, and chloroform. ${ }^{1} \mathrm{H}$ NMR (300 MHz, $\mathrm{CDCl}_{3}$ ): $\delta 4.24$ (s, 10H, Fc-Cp), 4.43 (pseudo-t, $4 \mathrm{H}, J=2.0 \mathrm{~Hz}, \mathrm{C} 3 / \mathrm{C} 4$ of substituted $\mathrm{Fc}-\mathrm{Cp}$ ), $5.01(\mathrm{~s}, 5 \mathrm{H}$, Co-Cp), 5.30 (pseudo-t, $4 \mathrm{H}, J=2.0 \mathrm{~Hz}, \mathrm{C} 2 / \mathrm{C} 5$ of substituted Fc-Cp) ppm. ${ }^{13} \mathrm{C} \mathrm{NMR}\left(75 \mathrm{MHz}, \mathrm{CDCl}_{3}\right): \delta 65.9(\mathrm{C} 3 / \mathrm{C} 4$ of substituted $\mathrm{Fc}-$ Cp), 67.0 (C2/C5 of substituted Fc-Cp), 70.7 (Fc-Cp), 78.2 (Co$\mathrm{Cp}$ ), 115.4 (quaternary carbon of substituted $\mathrm{Fc}-\mathrm{Cp}$ ) ppm. MS (ESI pos, $[\mathrm{m} / z]): 551.00[\mathrm{M}+\mathrm{H}]^{+}$. IR (ATR): $3078\left(\nu_{\mathrm{C}-\mathrm{H}}\right), 2923$ $\left(\nu_{\mathrm{C}-\mathrm{H}}\right), 1725,1448\left(\nu_{\mathrm{C}=\mathrm{C}}\right), 1411\left(\nu_{\mathrm{C}=\mathrm{C}}\right), 1251,998,813\left(\delta_{\mathrm{op}(\mathrm{C}-\mathrm{H})}\right)$, 523, $473\left(\nu_{\text {as }(\text { Co-ring })}\right) \mathrm{cm}^{-1}$. UV/vis $\left(\mathrm{CH}_{2} \mathrm{Cl}_{2}\right): \lambda_{\max } 419 \mathrm{~nm}(\varepsilon=6807$ $\left.\mathrm{L} \mathrm{mol}{ }^{-1} \mathrm{~cm}^{-1}\right), \lambda_{\max } 462 \mathrm{~nm}\left(\varepsilon=7124 \mathrm{~L} \mathrm{~mol}^{-1} \mathrm{~cm}^{-1}\right), \lambda_{\max } 759 \mathrm{~nm}$ $\left(\varepsilon=3997 \mathrm{~L} \mathrm{~mol}^{-1} \mathrm{~cm}^{-1}\right)$. Single crystals of $\mathbf{5}$ were obtained via diffusion crystallization in dichloromethane out of pentane: mp 197 ${ }^{\circ} \mathrm{C}$ (dec). Spectra and crystallographic data are given in the Supporting Information.

Azocobaltocenium Bis(hexafluoridophosphate) (6). A 100 $\mathrm{mL}$ round-bottom flask was charged with aminocobaltocenium hexafluoridophosphate $(8 ; 100.5 \mathrm{mg}, 0.2879 \mathrm{mmol}, 1$ equiv $), 30$ $\mathrm{mL}$ of $\mathrm{CH}_{2} \mathrm{Cl}_{2}, \mathrm{HgO}$ (184.7 mg, 0,7200 mmol, 2.5 equiv), and $\mathrm{I}_{2}$ ( $182.7 \mathrm{mg}, 0.7200 \mathrm{mmol}, 2.5$ equiv). The dispersion was stirred for 24 $\mathrm{h}$ under ambient conditions without protection from air. For workup, $30 \mathrm{~mL}$ of diethyl ether was added and the dispersion was filtered through a paper filter. From this filter the product was eluted with acetonitrile until a yellow coloring of the solvent was no longer seen. The yellow solution was evaporated to dryness on a rotary evaporator and dried in vacuo to yield an orange powder. If ${ }^{1} \mathrm{H}$ NMR showed an incomplete reaction, the product could be used again in the same reaction with an equivalent amount of $\mathrm{HgO}$ and $\mathrm{I}_{2}$ to yield $99 \%$ pure product. Yield: $86.9 \mathrm{mg}(0.125 \mathrm{mmol}, 87 \%)$. Compound 7 is air- and water-stable, soluble in acetonitrile, methanol, acetone, and nitromethane and moderately so in water. ${ }^{1} \mathrm{H} \mathrm{NMR}\left(300 \mathrm{MHz}, \mathrm{CD}_{3} \mathrm{CN}\right)$ : $\delta 5.26(\mathrm{~s}, 10 \mathrm{H}, \mathrm{Cp}), 5.91$ (pseudo-t, $4 \mathrm{H}, J=2.0 \mathrm{~Hz}, \mathrm{C} 3 / \mathrm{C} 4$ of substituted Cp), 6.30 (pseudo-t, $4 \mathrm{H}, J=2.0 \mathrm{~Hz}, \mathrm{C} 2 / \mathrm{C} 5$ of substituted $\mathrm{Cp}) \mathrm{ppm} .{ }^{13} \mathrm{C}$ NMR $\left(75 \mathrm{MHz}, \mathrm{CD}_{3} \mathrm{CN}\right): \delta 80.99(\mathrm{C} 3 / \mathrm{C} 4$ of substituted $\mathrm{Cp}$ ), 86.62 (C2/C5 of substituted Cp), 70.7 (Fc-Cp), $87.64(\mathrm{Cp}), 119.26$ (quaternary carbon of substituted Cp) ppm. MS
(ESI pos, $[\mathrm{m} / \mathrm{z}]): 202.0062[\mathrm{M}]^{+} / 2$ of dication; calcd, 202.0028. IR (ATR): $3124\left(\nu_{\mathrm{C}-\mathrm{H}}\right), 1419,1407,1032,904,813\left(\nu_{\mathrm{P}-\mathrm{F}}\right), 554\left(\nu_{\mathrm{P}-\mathrm{F}}\right)$, $541,508,466\left(\nu_{\text {as }(\text { Co-ring })}\right), 428 \mathrm{~cm}^{-1}$. UV/vis $\left(\mathrm{CH}_{3} \mathrm{OH}\right): \lambda_{\max } 292 \mathrm{~nm}$ $\left(\varepsilon=13200 \mathrm{~L} \mathrm{~mol}^{-1} \mathrm{~cm}^{-1}\right), \lambda_{\max } 356 \mathrm{~nm}\left(\varepsilon=5220 \mathrm{~L} \mathrm{~mol}^{-1} \mathrm{~cm}^{-1}\right)$, $\lambda_{\max } 427 \mathrm{~nm}\left(\varepsilon=1400 \mathrm{~L} \mathrm{~mol}^{-1} \mathrm{~cm}^{-1}\right)$. Single crystals of 6 were obtained from an acetonitrile solution: $\mathrm{mp} 180^{\circ} \mathrm{C}(\mathrm{dec})$. Spectra and crystallographic data are given in the Supporting Information.

\section{ASSOCIATED CONTENT}

\section{Supporting Information}

The Supporting Information is available free of charge on the ACS Publications website at DOI: 10.1021/acs.organomet.8b00681.

Spectra $\left({ }^{1} \mathrm{H} /{ }^{13} \mathrm{C}\right.$ NMR, IR, HRMS, UV-vis $)$, cyclic voltammograms, DFT results, crystal data, and a mechanistic scheme (PDF)

\section{Accession Codes}

CCDC 1867090-1867092 contain the supplementary crystallographic data for this paper. These data can be obtained free of charge via www.ccdc.cam.ac.uk/data request/cif, or by emailing data request@ccdc.cam.ac.uk, or by contacting The Cambridge Crystallographic Data Centre, 12 Union Road, Cambridge CB2 1EZ, UK; fax: +44 1223336033.

\section{AUTHOR INFORMATION}

\section{Corresponding Authors}

*E-mail for R.F.W: rainer.winter@uni-konstanz.de.

*E-mail for E.R.: reisner@ch.cam.ac.uk.

*E-mail for B.B.: benno.bildstein@uibk.ac.at.

\section{ORCID}

Souvik Roy: 0000-0003-0146-5283

Rainer F. Winter: 0000-0001-8381-0647

Benno Bildstein: 0000-0003-1969-1334

Notes

The authors declare no competing financial interest.

\section{ACKNOWLEDGMENTS}

B.B. thanks the Austrian Science Fund (FWF), grant P 30221, for financial support, E.R. the Christian Doppler Association (Austrian Federal Ministry for Digital and Economic Affairs, the National Foundation for Research, Technology and Development), and OMV for financial support, and S.R. for funding from the European Union's Horizon 2020 research and innovation program under the Marie Skłodowska-Curie Grant Agreement CO2RED No. 745604. R.F.W thanks the Deutsche Forschungsgemeinschaft (grant Wi1262/13-1) for financial support of this work and the state of BadenWürttemberg for providing us with access to the bW_HPC computational facilities at the KIT Karlsruhe.

\section{REFERENCES}

(1) Review: Comprehensive Coordination Chemistry, The Synthesis, Reactions, Properties \& Applications of Coordination Compounds; Wilkinson, G., Gillard, R. D., McCleverty, J. A., Eds.; Pergamon Press: Oxford, U.K., 1987; Vol. 2, Chapter 13.5, pp 217-224.

(2) Leading references: (a) Cenini, S.; La Monica, G. Organic azides and isocyanates as sources of nitrene species in organometallic chemistry. Inorg. Chim. Acta 1976, 18, 279-293. (b) Otsuka, S.; Nakamura, A. $\pi$-Cyclopentadienyl(1,4-tetraazendiyl)cobalt. Inorg. Chem. 1968, 7, 2542-2544. (c) Overbosch, P.; van Koten, G.; Overbeek, O. Conversion of aryl azides on nickel centers into tetraazadiene-nickel complexes $\left[\mathrm{Ni}^{0}\left(\mathrm{Ar}_{2} \mathrm{~N}_{4}\right)_{2}\right],\left[\mathrm{CpNi}{ }^{\mathrm{I}}\left(\mathrm{Ar}_{2} \mathrm{~N}_{4}\right)\right]$, and $\left[(\mathrm{RNC})_{2} \mathrm{Ni}^{0}\left(\mathrm{Ar}_{2} \mathrm{~N}_{4}\right)\right]$. Crystal structure of $\left[\mathrm{Ni}^{0}\{1,4-(3,5-\right.$ 
$\left.\left.\mathrm{Me}_{2} \mathrm{C}_{6} \mathrm{H}_{3}\right)_{2} \mathrm{~N}_{4}\right\}_{2}$ ]. J. Am. Chem. Soc. 1980, 102, 2091-2093. (d) Gross, M. E.; Trogler, W. C.; Ibers, J. A. Delocalized $\pi$ bonding in tetraazadiene metallocycles. J. Am. Chem. Soc. 1981, 103, 192-193. (e) Gross, M. E.; Trogler, W. C. Photochemical loss of dinitrogen from cyclopentadienylcobalt 1,4-diaryltetraazadienes. J. Organomet. Chem. 1981, 209, 407-414. (f) Overbosch, P.; van Koten, G.; Spek, A. L.; Roelofsen, G.; Duisenberg, A. J. M. Synthesis, reactivity, and crystal structure of [1,4-bis(4-tolyl)tetraazabutadiene $]\left(\eta^{5}\right.$ cyclopentadienyl)nickel. Inorg. Chem. 1982, 21, 3908-3913. (g) Overbosch, P.; van Koten, G.; Overbeek, O. Synthesis and reactivity of bis(1,4-diaryltetraazabutadiene)nickel complexes. Crystal and molecular structure of bis[1,4-bis(3,5-dimethylphenyl)tetraazabutadiene]nickel. Inorg. Chem. 1982, 21, 2373-2378. (h) Overbosch, P.; van Koten, G. Synthesis of metal-tetraazadiene complexes via $\mathrm{Ar}_{2} \mathrm{~N}_{4}$ ligand transfer. Evidence for a stable tetraazadiene-bridged intermediate. J. Organomet. Chem. 1982, 229, 193-202. (i) Maroney, M. J.; Trogler, W. C. Redox chemistry of cyclopentadienylcobalt tetraazabutadienes. Characterization of 19-electron anionic complexes. J. Am. Chem. Soc. 1984, 106, 4144-4151. (j) Lee, S. W.; Trogler, W. C. Synthesis, Structure, and Properties of Dicarbonyl Bis(phosphine)1,4-Diphenyltetraazabutadiene Complexes of Molybdenum and Tungsten. Organometallics 1990, 9, 1470-1478. (k) Cowley, R. E.; Bill, E.; Neese, F.; Brennessel, W. W.; Holland, P. L. Iron(II) Complexes with Redox-Active Tetrazene (RNNNNR) Ligands. Inorg. Chem. 2009, 48, 4828-4836. (1) Vaddypally, S.; McKendry, I. G.; Tomlinson, W.; Hooper, J. P.; Zdilla, M. J. Electronic Structure of Manganese Complexes of the Redox-Noninnocent Tetrazene Ligand and Evidence for the Metal-Azide/Imido Cycloaddition Intermediate. Chem. - Eur. J. 2016, 22, 10548-10557. (m) Elpitiya, G. R.; Malbrecht, B. J.; Jenkins, D. M. A Chromium(II) Tetracarbene Complex Allows Unprecedented Oxidative Group Transfer. Inorg. Chem. 2017, 56, 14101-14110. (n) Bowman, A. C.; Tondreau, A. M.; Lobkovsky, E.; Margulieux, G. W.; Chirik, P. J. Synthesis and Electronic Structure Diversity of Pyridine(diimine)iron Tetrazene Complexes. Inorg. Chem. 2018, 57, 9634-9643.

(3) Vanicek, S.; Kopacka, H.; Wurst, K.; Müller, T.; Hassenrück, C.; Winter, R. F.; Bildstein, B. Monofunctionalized Cobaltocenium Compounds by Dediazoniation Reactions of Cobaltoceniumdiazonium Bis(hexafluorophosphate). Organometallics 2016, 35, 21012109.

(4) (a) Nesmeyanov, A. N.; Drozd, V. N.; Sazanova, V. A. Azids of ferrocene. Dokl. Akad. Nauk SSR 1963, 150, 321-324. (b) Tennyson, A. G.; Khramov, D. M.; Varnado, C. D., Jr.; Creswell, P. T.; Kamplain, J. W.; Lynch, V. M.; Bielawski, C. W. Indirectly Connected Bis(NHeterocyclic Carbene) Bimetallic Complexes: Dependence of MetalMetal Electronic Coupling on Linker Geometry. Organometallics 2009, 28, 5142-5147.

(5) Selected reviews: (a) Artero, V.; Chavarot-Kerlidou, M.; Fontecave, M. Splitting Water with Cobalt. Angew. Chem., Int. Ed. 2011, 50, 7238-7266. (b) Dempsey, J. L.; Brunschwig, B. S.; Winkler, J. R.; Gray, H. B. Hydrogen Evolution Catalyzed by Cobaloximes. Acc. Chem. Res. 2009, 42, 1995-2004.

(6) Bönnemann, H. Organocobaltverbindungen in der Pyridinsynthese - ein Beispiel für Struktur-Wirkungs-Beziehungen in der Homogenkatalyse. Angew. Chem. 1985, 97, 264-279 and references therein .

(7) Platz, M. S. Comparison of Phenylcarbene and Phenylnitrene. Acc. Chem. Res. 1995, 28, 487-492.

(8) (a) Nesmeyanov, A. N.; Perevalova, E. G.; Nikitina, T. V. Azoferrocene synthesis, reduction and behaviour under conditions of benzidine regrouping. Dokl. Akad. Nauk SSR 1961, 138, 1118-1121. (b) Nesmeyanov, A. N.; Perevalova, E. G.; Nikitina, T. V. Azoferrocene. Tetrahedron Lett. 1960, 1, 1-2. (c) Kurihara, M.; Matsuda, T.; Hirooka, A.; Yutaka, T.; Nishihara, H. Novel Photoisomerization of Azoferrocene with a Low-Energy MLCT Band and Significant Change of the Redox Behavior between the cisand trans-Isomers. J. Am. Chem. Soc. 2000, 122, 12373-12374; 2004, 126, 4740 (correction) DOI: 10.1021/ja040803c. (d) Kurosawa, M.; Nankawa, T.; Matsuda, T.; Kubo, K.; Kurihara, M.; Nishihara, H.
Synthesis of Azo-Bridged Ferrocene Oligomers and a Polymer and Electrochemical and Optical Analysis of Internuclear Electronic Interactions in Their Mixed-Valence States. Inorg. Chem. 1999, 38, 5113-5123. (e) Powers, I. G.; Andjaba, J. M.; Luo, X.; Mei, J.; Uyeda, C. Catalytic Azoarene Synthesis from Aryl Azides Enabled by a Dinuclear Ni Complex. J. Am. Chem. Soc. 2018, 140, 4110-4118.

(9) Orito, K.; Hatakeyama, T.; Takeo, M.; Uchiito, S.; Tokuda, M.; Suginome, H. Dimerization of anilines and benzylamines with mercury(II) oxide-iodine reagent. Tetrahedron 1998, 54, 8403-8410.

(10) (a) Vanicek, S.; Podewitz, M.; Stubbe, J.; Schulze, D.; Kopacka, H.; Wurst, K.; Müller, T.; Lippmann, P.; Haslinger, S.; Schottenberger, H.; Liedl, K. R.; Ott, I.; Sarkar, B.; Bildstein, B. Highly Electrophilic, Catalytically Active and Redox-Responsive Cobaltoceniumyl and Ferrocenyl Triazolylidene Coinage Metal Complexes. Chem. - Eur. J. 2018, 24, 3742-3753. (b) Vanicek, S.; Podewitz, M.; Hassenrück, C.; Pittracher, M.; Kopacka, H.; Wurst, K.; Müller, T.; Liedl, K. R.; Winter, R. F.; Bildstein, B. Cobaltocenylidene: A Mesoionic Metalloceno Carbene, Stabilized in a Gold(III) Complex. Chem. - Eur. J. 2018, 24, 3165-3169. (c) Vanicek, S.; Wurst, K.; Bildstein, B. Cobaltoceniumsulfonate. IUCrData 2017, 2, x171703. (d) Vanicek, S.; Kopacka, H.; Wurst, K.; Vergeiner, S.; Kankowski, S.; Schur, J.; Bildstein, B.; Ott, I. Cobaltoceniumethynyl gold(I) as an unusual heterodinuclear bioorganometallic fragment to study the biological properties of alkynyl gold complexes. Dalton Trans. 2016, 45, 1345-1348. (e) Vanicek, S.; Kopacka, H.; Wurst, K.; Vergeiner, S.; Oehninger, L.; Ott, I.; Bildstein, B. Cobaltocenium Carboxylate Transition Metal Complexes: Synthesis, Structure, Reactivity, and Cytotoxicity. Z. Anorg. Allg. Chem. 2015, 641, 1282-1292. (f) Vanicek, S.; Kopacka, H.; Wurst, K.; Müller, T.; Schottenberger, H.; Bildstein, B. Chemoselective, Practical Synthesis of Cobaltocenium Carboxylic Acid Hexafluorophosphate. Organometallics 2014, 33, 1152-1156.

(11) Heyns, A. M. The i.r. and Raman spectra of sodium hexafluorophosphate monohydrate, $\mathrm{NaPF}_{6} \cdot \mathrm{H}_{2} \mathrm{O}$. Spectrochim. Acta 1977, 33, 315-322.

(12) Delgado-Pena, F.; Talham, D. R.; Cowan, D. O. Near-IR spectroscopic studies of mixed-valence di-, tri-, and tetraferrocene derivatives. J. Organomet. Chem. 1983, 253, C43-C46.

(13) Krejcik, M.; Danek, M.; Hartl, F. Simple construction of an infrared optically transparent thin-layer electrochemical cell: Applications to the redox reactions of ferrocene, $\mathrm{Mn}_{2}(\mathrm{CO})_{10}$ and $\mathrm{Mn}$ $(\mathrm{CO})_{3}(3,5 \text {-di-t-butyl-catecholate })^{-}$. J. Electroanal. Chem. Interfacial Electrochem. 1991, 317, 179-187.

(14) Connelly, N. G.; Geiger, W. E. Chemical Redox Agents for Organometallic Chemistry. Chem. Rev. 1996, 96, 877-910.

(15) Fourmond, V.; Jacques, P.-A.; Fontecave, M.; Artero, V. $\mathrm{H}_{2}$ Evolution and Molecular Electrocatalysts: Determination of Overpotentials and Effect of Homoconjugation. Inorg. Chem. 2010, 49, 10338-10347.

(16) (a) Costentin, C.; Saveant, J.-M. Multielectron, Multistep Molecular Catalysis of Electrochemical Reactions: Benchmarking of Homogeneous Catalysts. ChemElectroChem 2014, 1, 1226-1236. (b) Costentin, C.; Drouet, S.; Robert, M.; Saveant, J.-M. Turnover Numbers, Turnover Frequencies, and Overpotential in Molecular Catalysis of Electrochemical Reactions. Cyclic Voltammetry and Preparative-Scale Electrolysis. J. Am. Chem. Soc. 2012, 134, 1123511242.

(17) Frisch, M. J.; Trucks, G.; Schlegel, H. B.; Scuseria, G. E.; Robb, M. A.; Cheeseman, J. R.; Scalmani, G.; Barone, V.; Mennucci, B.; Petersson, G. A.; Nakatsuji, H.; Caricato, M.; Li, X.; Hratchian, H. P.; Izmaylov, A. F.; Blonio, J.; Zheng, G.; Sonnenberg, J. L.; Hada, M.; Ehara, M.; Toyota, K.; Fukuda, R.; Hasegawa, J.; Ishida, M.; Nakajima, T.; Honda, Y.; Kitao, O.; Nakai, H.; Vreven, T.; Peralta, J.; Montgomery, J. A., Jr.; Ogliaro, F.; Bearpark, M.; Heyd, J. J.; Brothers, E.; Kudin, K. N.; Staroverov, V. N.; Keith, T.; Kobayashi, R.; Normand, J.; Raghavachari, K.; Rendell, A.; Burant, J. C.; Iyengar, S. S.; Tomasi, J.; Cossi, M.; Rega, N.; Millam, J. M.; Klene, M.; Knox, J. E.; Cross, J. B.; Bakken, V.; Adamo, C.; Jaramillo, J.; Gomperts, R.; Stratmann, R. E.; Yazyev, O.; Austin, A. J.; Cammi, R.; Pomelli, C.; 
Ochterski, J. W.; Martin, R. L.; Morokuma, K.; Zakrzewski, V. G.; Voth, G. A.; Salvador, P.; Dannenberg, J. J.; Dapprich, S.; Daniels, A. D.; Farkas, O.; Foresman, J. B.; Ortiz, J. V.; Cioslowski, J.; Fox, D. J. Gaussian 09, Revision B.01; Gaussian Inc., Wallingford, CT, 2010.

(18) Andrae, D.; Haeussermann, U.; Dolg, M.; Stoll, H.; Preuss, H. Energy-adjusted $a b$ initio pseudopotentials for the second and third row transition elements. Theor. Chim. Acta 1990, 77, 123-141.

(19) Perdew, J. P.; Burke, K.; Ernzerhof, M. Generalized Gradient Approximation Made Simple. Phys. Rev. Lett. 1996, 77, 3865-3868.

(20) Cossi, M.; Rega, N.; Scalmani, G.; Barone, V. Energies, structures, and electronic properties of molecules in solution with the C-PCM solvation model. J. Comput. Chem. 2003, 24, 669-681. 